\title{
Linguistic Interval-Valued Intuitionistic Fuzzy Archimedean Prioritised Aggregation Operators for Multi-Criteria Decision Making
}

\author{
Yuchu Qin, Qunfen Qi ${ }^{*}$, Peizhi Shi, Paul J. Scott, and Xiangqian Jiang \\ School of Computing and Engineering, University of Huddersfield, Huddersfield, West Yorkshire, UK
}

\begin{abstract}
Two key steps in multi-criteria decision making (MCDM) are to quantify the considered criteria and to fuse the quantified criterion information to sort all alternatives. One of the most recent and important tools for the first step is linguistic interval-valued intuitionistic fuzzy number (LIVIFN) and one of the most common and effective ways for the second step is aggregation operator (AO). So far, a number of AOs of LIVIFNs have been presented. Each AO can work well under certain conditions. But there is not yet an AO of LIVIFNs that can deal with the situation where the weights of the considered criteria are unknown and the criteria are in different priority levels and concurrently provide satisfying generality and flexibility in the aggregation of criterion information. To this end, a linguistic interval-valued intuitionistic fuzzy Archimedean prioritised and (LIVIFAPA) operator and a linguistic interval-valued intuitionistic fuzzy Archimedean prioritised or (LIVIFAPO) operator, which have such capabilities, are presented in this paper. The formal definitions and generalised expressions of the two AOs are firstly provided. Then their properties are explored and proved and specific expressions are established. After that, a new method for solving the LIVIFNs based MCDM problems is proposed on the basis of the presented AOs. Finally, the proposed method is illustrated via an example about additive manufacturing machine selection and is evaluated via a comparison with existing methods. The major contribution of the paper is the development of the LIVIFAPA and LIVIFAPO operators for MCDM, which can make up for the above shortcoming of the existing AOs of LIVIFNs.
\end{abstract}

Keywords: Prioritised and operator, prioritised or operator, linguistic interval-valued intuitionistic fuzzy set, Archimedean tnorm and t-conorm, multi-criteria decision making

\section{Introduction}

Multi-criteria decision-making (MCDM) refers to a decision-making process of sorting all alternatives or selecting the optimal alternative through considering multiple criteria comprehensively [1]. As an important sub-discipline of operations research, MCDM has received extensive attention from researchers and its theory and methods have been applied to a number of fields, such as engineering, economics, management, and military [2]. In the process of MCDM, there are two key steps. The first key step is to accurately and effectively quantify the considered criteria, while the second key step is to aggregate the quantified criterion information to sort all alternatives.

For the quantification of the criteria, real number is one of the simplest and most straightforward tools.
However, it is usually difficult to quantify the considered criteria in crisp values due to ambiguity, incompleteness, and uncertainty of the criterion information. To this end, fuzzy sets were introduced to MCDM and have become one of the most effective tools for quantification of the considered criteria. So far, over thirty different types of fuzzy sets, such as fuzzy set (FS) [3], intuitionistic FS (IFS) [4], interval-valued IFS [5], linguistic IFS [6], and linguistic interval-valued IFS (LIVIFS) [7, 8], have been presented within academia [9]. The LIVIFS, which was presented by Liu and Qin [7] and Garg and Kumar [8], is considered as one of the most recent and important types.

A LIVIFS consists of an element and a membership degree and a non-membership degree of the element to the LIVIFS, in which each degree is de-

\footnotetext{
*Corresponding author. E-mail: q.qi@hud.ac.uk.
} 
scribed using an interval of two linguistic variables, e.g. [very bad, bad], [very good, extremely good]. A pair of the two degrees is generally called linguistic interval-valued intuitionistic fuzzy number (LIVIFN). Compared with FS, IFS, interval-valued IFS, and linguistic IFS, LIVIFS can provide stronger expressiveness and more freedom, because it allows the use of intervals of linguistic terms to describe values of the considered criteria. Due to such characteristic, the research and application of LIVIFSs in the field of MCDM are gaining importance [10-13].

For the aggregation of the criterion information to sort alternatives, traditional decision-making methods [14-25], such as analytic hierarchy process, VIKOR, TOPSIS, ELECTRE, and PROMETHEE, and aggregation operators (AOs) [26-40] are two of the most common and effective ways. AOs can solve MCDM problems more effectively than traditional methods, since they can generate both the overall criterion value of each alternative and a ranking of all alternatives, while traditional methods can only generate a ranking [41]. To date, many AOs of LIVIFNs have been presented. Representative ones are the weighted average (WA), ordered WA (OWA), hybrid average (HA), weighted geometric (WG), ordered WG (OWG), and hybrid geometric (HG) operators presented by Garg and Kumar [7], the weighted Maclaurin symmetric mean (WMSM) operator presented by Liu and Qin [8], and the prioritised weighted averaging (PWA), prioritised ordered weighted averaging (POWA), prioritised weighted geometric (PWG), and prioritised ordered weighted geometric (POWG) operators presented by Kumar and Garg [10]. The WA, OWA, HA, WG, OWG, and HG operators are applicable when all criteria are mutually independent and the weights of criteria are known. The WMSM operator was developed for handling the interrelated relationship among different criteria under known weights of criteria. The PWA, POWA, PWG, and POWG operators are suitable for the situation in which the criteria are in different priority levels and their weights are unknown.

In actual MCDM problems, various relationships usually exist among different considered criteria. In addition to the independent and interrelated relationships mentioned above, priority relationship is another common type [42]. In a MCDM problem with a priority relationship, the weights of the considered criteria are unknown and the criteria are in different priority levels. To produce reasonable result for such MCDM problem, it is of necessity to use an AO that can capture the priority relationship. Among the existing AOs of LIVIFNs, the PWA, POWA, PWG, and POWG operators have such capability. Further, the relationships of criteria could change as the actual situation changes. An ideal AO should have generality and flexibility to adapt to these changes. The existing AOs of LIVIFNs, however, are not general and flexible enough, since the aggregation in all of them is achieved through the fixed Algebraic t-norm and tconorm operation. Based on these considerations, the motivations of the present paper are summarised as follows:

(1) To develop AOs of LIVIFNs that can capture the priority relationship among criteria, the prioritised AOs presented by Yager [43] are introduced to LIVIFSs. Yager's prioritised AOs are well-known for having the capability to capture the priority relationship of the aggregated arguments. They have been applied to a number of fuzzy sets, such as IFSs [44, 45], hesitant FSs [46, 47], Pythagorean FSs [48, 49], neutrosophic sets [50], bipolar FSs [51], intuitionistic fuzzy soft sets [52], hesitant bipolar FSs [53], linguistic IFS [54], hesitant fuzzy linguistic sets [55], single-valued neutrosophic sets [56], linguistic interval-valued sets [57], and LIVIFSs [10], to solve the MCDM problems.

(2) To improve the generality and flexibility in aggregating criterion information of the developed AOs of LIVIFNs, the Archimedean t-norm and t-conorm (ATT) [58] are adopted to carry out their operations. The ATT are effective mathematical tools for developing versatile operational laws for fuzzy numbers. A fuzzy information AO based on them is rather versatile and flexible [41].

Based on the motivations above, this paper combines the Yager's prioritised AOs with the operations based on ATT in LIVIFS environment to construct linguistic interval-valued intuitionistic fuzzy Archimedean prioritised operators of LIVIFNs for MCDM problems based on LIVIFNs. The novelty of the paper is reflected in the constructed operators have the capability to capture the priority relationship among criteria and concurrently have desirable generality and flexibility in aggregating criterion information. Although there are already four prioritised AOs of LIVIFNs (i.e. the PWA, POWA, PWG, and POWG operators in [10]), the constructed operators are still of necessity as they are more general and flexible. The PWA, POWA, PWG, and POWG operators are based on the Algebraic t-norm and t-conorm, one of the many families of ATT, while the constructed operators can be applied any families of ATT.

The remainder of the paper is organised as follows. A brief introduction of some prerequisites is provided Section 2. Section 3 explains the details of the con- 
structed AOs of LIVIFNs. A MCDM method based on the AOs is designed in Section 4. Section 5 reports an illustration of the designed MCDM method and a comparison with existing MCDM methods. A conclusion of the paper is drawn in Section 6.

\section{Preliminaries}

In this section, some prerequisites in the LIVIFS theory, operational laws for LIVIFNs, and prioritised AOs are briefly introduced to facilitate the understanding of the present paper.

\subsection{LIVIFS theory}

The concept of LIVIFS was presented by Liu and Qin [7] and Garg and Kumar [8]. Its formal definition is as follow:

Definition $1[7,8]$. Let $S_{[0, h]}=\left\{s_{t} \mid s_{0} \leq s_{t} \leq s_{h}\right\}$ (where $h$ is a positive integer) be a continuous linguistic term set such that for any $s_{i}, s_{j} \in S_{[0, h]}, s_{i}>s_{j}$ if and only if $i>j$. Then a LIVIFS $A$ in a finite universe of discourse $X$ is

$$
A=\left\{\left\langle x,\left[s_{\mu_{L}(x)}, s_{\mu_{U}(x)}\right],\left[s_{v_{L}(x)}, s_{v_{U}(x)}\right]\right\rangle \mid x \in X\right\}
$$

where

$$
\left[s_{\mu_{L}(x)}, s_{\mu_{U}(x)}\right],\left[s_{v_{L}(x)}, s_{v_{U}(x)}\right] \subseteq\left[s_{0}, s_{h}\right]
$$

are respectively the linguistic membership degree and non-membership degree of $x$ to $A$ such that for any $x \in X$,

$$
\left.s_{\mu_{U}(x)}+s_{v_{U}(x)} \leq s_{h} \text { (i.e. } \mu_{U}(x) / h+v_{U}(x) / h \leq 1\right)
$$

The linguistic intuitionistic index of $x$ to $A$ is

$$
\left[s_{\pi_{L}(x)}, s_{\pi_{U}(x)}\right]=\left[s_{\left(h-\mu_{U}(x)-v_{U}(x)\right)}, s_{\left(h-\mu_{L}(x)-v_{L}(x)\right)}\right]
$$

In a LIVIFS, the pair

$$
\alpha=\left(\left[s_{\mu_{L}(x)}, s_{\mu_{U}(x)}\right],\left[s_{v_{L}(x)}, s_{v_{U}(x)}\right]\right)
$$

is called as a LIVIFN. For the sake of simplicity, a LIVIFN is usually denoted as $\alpha=\left(\left[s_{a}, s_{b}\right],\left[s_{c}, s_{d}\right]\right)$ such that $\left[s_{a}, s_{b}\right],\left[s_{c}, s_{d}\right] \subseteq\left[s_{0}, s_{h}\right]$ and $b / h+d / h \leq 1$. To compare two LIVIFNs, their score and accuracy values are needed. Such values can be respectively calculated by a score function and an accuracy function. The followings are respectively the score and accuracy functions of a LIVIFN:

$$
\begin{aligned}
& S(\alpha)=(2 h+a+b-c-d) / 4 \\
& A(\alpha)=(a+b+c+d) / 2
\end{aligned}
$$

Any two LIVIFNs can be compared according to the rules presented by Liu and Qin [7] and Garg and
Kumar [8] once their score and accuracy values are calculated. Formally, let

$$
\begin{aligned}
& \alpha_{1}=\left(\left[s_{a_{1}}, s_{b_{1}}\right],\left[s_{c_{1}}, s_{d_{1}}\right]\right) \\
& \alpha_{2}=\left(\left[s_{a_{2}}, s_{b_{2}}\right],\left[s_{c_{2}}, s_{d_{2}}\right]\right)
\end{aligned}
$$

be any two LIVIFNs, $S\left(\alpha_{1}\right)$ and $S\left(\alpha_{2}\right)$ be respectively the score values of $\alpha_{1}$ and $\alpha_{2}$, and $A\left(\alpha_{1}\right)$ and $A\left(\alpha_{2}\right)$ be respectively the accuracy values of $\alpha_{1}$ and $\alpha_{2}$. Then:

(1) If $S\left(\alpha_{1}\right)>S\left(\alpha_{2}\right)$, then $\alpha_{1}>\alpha_{2}$;

(2) If $S\left(\alpha_{1}\right)=S\left(\alpha_{2}\right)$ and $A\left(\alpha_{1}\right)>A\left(\alpha_{2}\right)$, then $\alpha_{1}>\alpha_{2}$;

(3) If $S\left(\alpha_{1}\right)=S\left(\alpha_{2}\right)$ and $A\left(\alpha_{1}\right)=A\left(\alpha_{2}\right)$, then $\alpha_{1}=\alpha_{2}$.

\subsection{Operational laws for LIVIFNs}

Motivated by t-norm and t-conorm, a set of operational laws for LIVIFNs based on the Algebraic tnorm and t-conorm were presented by Liu and Qin [7] and Garg and Kumar [8]. These laws are not general and flexible enough as they are just based on a specific family of ATT. Inspired by the versatile operational laws for q-rung orthopair fuzzy numbers that are based on any families of ATT [41], a set of operational laws for LIVIFNs based on ATT is developed. The definition of the developed operational laws is as follow:

Definition 2 [7, 8]. Let

$$
\begin{aligned}
& \alpha_{1}=\left(\left[s_{a_{1}}, s_{b_{1}}\right],\left[s_{c_{1}}, s_{d_{1}}\right]\right) \\
& \alpha_{2}=\left(\left[s_{a_{2}}, s_{b_{2}}\right],\left[s_{c_{2}}, s_{d_{2}}\right]\right)
\end{aligned}
$$

and $\alpha=\left(\left[s_{a}, s_{b}\right],\left[s_{c}, s_{d}\right]\right)$ be any three LIVIFNs, and $r$ be a positive real number. Then the operations of LIVIFNs based on the Archimedean t-norm $T(x, y)=$ $f^{-1}(f(x)+f(y))$ and its t-conorm $C(x, y)=g^{-1}(g(x)+$ $g(y))$ are respectively defined as follows:

$$
\begin{aligned}
& \alpha_{1} \oplus \alpha_{2}=\left(\left[s_{\left(C\left(a_{1}, a_{2}\right)\right)}, s_{\left(C\left(b_{1}, b_{2}\right)\right)}\right],\right. \\
& \left.\left[s_{\left(T\left(c_{1}, c_{2}\right)\right)}, s_{\left(T\left(d_{1}, d_{2}\right)\right)}\right]\right)= \\
& \left(\left[s_{\left(g^{-1}\left(g\left(a_{1}\right)+g\left(a_{2}\right)\right)\right)}, s_{\left(g^{-1}\left(g\left(b_{1}\right)+g\left(b_{2}\right)\right)\right)}\right],\right. \\
& \left.\left[s_{\left(f^{-1}\left(f\left(c_{1}\right)+f\left(c_{2}\right)\right)\right)}, s_{\left(f^{-1}\left(f\left(d_{1}\right)+f\left(d_{2}\right)\right)\right)}\right]\right) \\
& \alpha_{1} \otimes \alpha_{2}=\left(\left[s_{\left(T\left(a_{1}, a_{2}\right)\right)}, s_{\left(T\left(b_{1}, b_{2}\right)\right)}\right],\right. \\
& \left.\left[s_{\left(C\left(c_{1}, c_{2}\right)\right)}, s_{\left(C\left(d_{1}, d_{2}\right)\right)}\right]\right)= \\
& \left(\left[s_{\left(f^{-1}\left(f\left(a_{1}\right)+f\left(a_{2}\right)\right)\right)}, s_{\left(f^{-1}\left(f\left(b_{1}\right)+f\left(b_{2}\right)\right)\right)}\right],\right. \\
& \left.\left[s_{\left(g^{-1}\left(g\left(c_{1}\right)+g\left(c_{2}\right)\right)\right)}, s_{\left(g^{-1}\left(g\left(d_{1}\right)+g\left(d_{2}\right)\right)\right)}\right]\right)
\end{aligned}
$$




$$
\begin{aligned}
& r \alpha=\left(\left[s_{\left(g^{-1}\left(r g\left(a_{\alpha}\right)\right)\right)}, s_{\left(g^{-1}\left(r g\left(b_{\alpha}\right)\right)\right)}\right],\right. \\
& \left.\left[s_{\left(f^{-1}\left(r f\left(c_{\alpha}\right)\right)\right)}, s_{\left(f^{-1}\left(r f\left(d_{\alpha}\right)\right)\right)}\right]\right) \\
& \alpha^{r}=\left(\left[s_{\left(f^{-1}\left(r f\left(a_{\alpha}\right)\right)\right)}, s_{\left(f^{-1}\left(r f\left(b_{\alpha}\right)\right)\right)}\right],\right. \\
& \left.\left[s_{\left(g^{-1}\left(r g\left(c_{\alpha}\right)\right)\right)}, s_{\left(g^{-1}\left(r g\left(d_{\alpha}\right)\right)\right)}\right]\right)
\end{aligned}
$$

\subsection{Prioritised AOs of crisp numbers}

The prioritised AOs were presented by Yager [43]. They have the capability to capture the priority relationship of arguments through making the weight of an argument dependent upon the satisfaction of the higher priority arguments. The prioritised AOs mainly include a prioritised and (PA) operator and a prioritised or (PO) operator. The formal definitions of the two operators are respectively as follows:

Definition 3 [43]. Let $\left(x_{1}, x_{2}, \ldots, x_{n}\right)$ be a collection of $n$ crisp numbers, $S=\left\{x_{1}, x_{2}, \ldots, x_{n}\right\}$ be an ordered set of $x_{1}, x_{2}, \ldots, x_{n}$,

$$
\boldsymbol{S}_{k}=\left\{x_{1_{k}}, x_{2_{k}}, \ldots, x_{\left|S_{k}\right|_{k}}\right\}(k=1,2, \ldots, N)
$$

be $N$ partitions of $S, S_{1}>S_{2}>\ldots>S_{N}$ be the priority relationship among $S_{1}, S_{2}, \ldots, S_{N}, T_{0}=1$, and

$$
T_{k}=\min \left(x_{1_{k}}, x_{2_{k}}, \ldots, x_{\left|S_{k}\right|_{k}}\right)
$$

Then the aggregation function

$$
P A\left(x_{1}, x_{2}, \ldots, x_{n}\right)=\prod_{k=1}^{N}\left(\prod_{i_{k}=1}^{\left|S_{k}\right|}\left(x_{i_{k}}\right) \prod_{j=0}^{k-1} T_{j}\right)
$$

is called as the PA operator.

Definition 4 [43]. Let $\left(x_{1}, x_{2}, \ldots, x_{n}\right)$ be a collection of $n$ crisp numbers, $S=\left\{x_{1}, x_{2}, \ldots, x_{n}\right\}$ be an ordered set of $x_{1}, x_{2}, \ldots, x_{n}$,

$$
\boldsymbol{S}_{k}=\left\{x_{1_{k}}, x_{2_{k}}, \ldots, x_{\left|S_{k}\right|_{k}}\right\}(k=1,2, \ldots, N)
$$

be $N$ partitions of $\boldsymbol{S}, \boldsymbol{S}_{1}>\boldsymbol{S}_{2}>\ldots>\boldsymbol{S}_{N}$ be the priority relationship among $S_{1}, S_{2}, \ldots, S_{N}, T_{0}=1$, and

$$
T_{k}=\max \left(x_{1_{k}}, x_{2_{k}}, \ldots, x_{\left|S_{k}\right|_{k}}\right)
$$

Then the aggregation function

$$
P O\left(x_{1}, x_{2}, \ldots, x_{n}\right)=\sum_{k=1}^{N} \sum_{i_{k}=1}^{\left|S_{k}\right|}\left(\left(\prod_{j=0}^{k-1} T_{j}\right) x_{i_{k}}\right)
$$

is called as the PO operator.

\section{Archimedean Prioritised AOs of LIVIFNs}

In this section, a linguistic interval-valued intuitionistic fuzzy Archimedean PA (LIVIFAPA) operator and a linguistic interval-valued intuitionistic fuzzy Archimedean PO (LIVIFAPO) operator are presented. The formal definitions and generalised expressions of the two AOs are provided. Then their properties are explored and specific expressions are established.

\subsection{LIVIFAPA operator}

A LIVIFAPA operator is a PA operator of LIVIFNs, in which all operations are carried out via the ATT based operational laws for LIVIFNs. The formal definition of this operator is as follow:

Definition 5. Let $\left(\alpha_{1}, \alpha_{2}, \ldots, \alpha_{n}\right)$ (where

$$
\alpha_{i}=\left(\left[s_{a_{i}}, s_{b_{i}}\right],\left[s_{c_{i}}, s_{d_{i}}\right]\right)(i=1,2, \ldots, n)
$$

) be a collection of $n$ LIVIFNs, $S=\left\{\alpha_{1}, \alpha_{2}, \ldots, \alpha_{n}\right\}$ be an ordered set of $\alpha_{1}, \alpha_{2}, \ldots, \alpha_{n}$,

$$
\boldsymbol{S}_{k}=\left\{\alpha_{1_{k}}, \alpha_{2_{k}}, \ldots, \alpha_{\left|S_{k}\right|_{k}}\right\}(k=1,2, \ldots, N)
$$

be $N$ partitions of $\boldsymbol{S}, \boldsymbol{S}_{1}>\boldsymbol{S}_{2}>\ldots>\boldsymbol{S}_{N}$ be the priority relationship among $S_{1}, S_{2}, \ldots, S_{N}, T_{0}=\left(\left[s_{h}, s_{h}\right],\left[s_{0}\right.\right.$, $\left.s_{0}\right]$,

$$
\begin{aligned}
& T_{k}=\left(\left[s_{\min \left(a_{i k}\right)}, s_{\min \left(b_{i k}\right)}\right],\left[s_{\max \left(c_{i k}\right)}, s_{\max \left(d_{i k}\right)}\right]\right) \\
& w_{k}=S\left(\bigotimes_{j=0}^{k-1} T_{j}\right) / \sum_{p=1}^{N} S\left(\bigotimes_{q=0}^{p-1} T_{q}\right)
\end{aligned}
$$

(where $S$ is the score function defined in Eq. (1)), $\alpha_{i} \otimes \alpha_{j}(j=1,2, \ldots, n)$ be the product operation of $\alpha_{i}$ and $\alpha_{j}$ based on ATT, and $\alpha_{i}^{r}(r>0)$ be the power operation of $\alpha_{i}$ based on ATT. Then the aggregation function

$$
\operatorname{LIVIFAPA}\left(\alpha_{1}, \alpha_{2}, \ldots, \alpha_{n}\right)=\bigotimes_{k=1 i_{k}=1}^{N} \bigotimes_{i_{k}}\left|S_{k}\right|
$$

is called as the LIVIFAPA operator.

According to Eq.s (3)-(6) and (9), the following theorem is obtained:

Theorem 1. Let $\left(\alpha_{1}, \alpha_{2}, \ldots, \alpha_{n}\right)$ (where

$$
\alpha_{i}=\left(\left[s_{a_{i}}, s_{b_{i}}\right],\left[s_{c_{i}}, s_{d_{i}}\right]\right)(i=1,2, \ldots, n)
$$

) be a collection of $n$ LIVIFNs, $S=\left\{\alpha_{1}, \alpha_{2}, \ldots, \alpha_{n}\right\}$ be an ordered set of $\alpha_{1}, \alpha_{2}, \ldots, \alpha_{n}$,

$$
\boldsymbol{S}_{k}=\left\{\alpha_{1_{k}}, \alpha_{2_{k}}, \ldots, \alpha_{\left|S_{k}\right|_{k}}\right\}(k=1,2, \ldots, N)
$$

be $N$ partitions of $\boldsymbol{S}$, and $\boldsymbol{S}_{1}>\boldsymbol{S}_{2}>\ldots>\boldsymbol{S}_{N}$ be the priority relationship among $\boldsymbol{S}_{1}, \boldsymbol{S}_{2}, \ldots, \boldsymbol{S}_{N}$. Then 


$$
\begin{aligned}
& \operatorname{LIVIFAPA}\left(\alpha_{1}, \alpha_{2}, \ldots, \alpha_{n}\right)=
\end{aligned}
$$

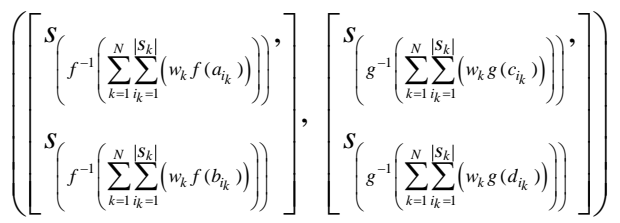

where

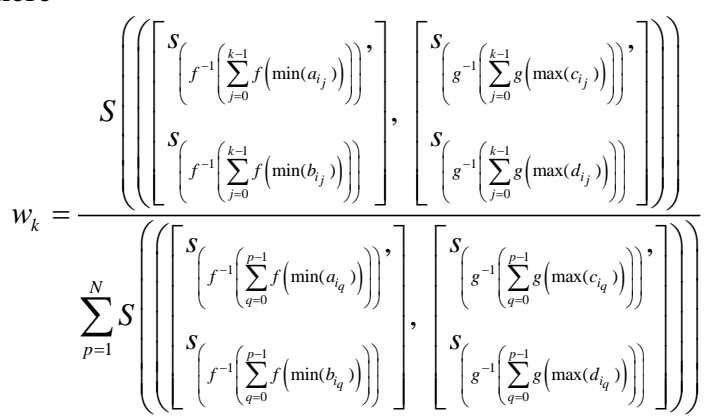

and it is still a LIVIFN.

The proof of this theorem is provided in App. A. The LIVIFAPA operator has the following property:

Theorem 2 (Idempotency). Let $\left(\alpha_{1}, \alpha_{2}, \ldots, \alpha_{n}\right)$ (where

$$
\alpha_{i}=\left(\left[s_{a_{i}}, s_{b_{i}}\right],\left[s_{c_{i}}, s_{d_{i}}\right]\right)(i=1,2, \ldots, n)
$$

) be a collection of $n$ LIVIFNs, $S=\left\{\alpha_{1}, \alpha_{2}, \ldots, \alpha_{n}\right\}$ be an ordered set of $\alpha_{1}, \alpha_{2}, \ldots, \alpha_{n}$,

$$
\boldsymbol{S}_{k}=\left\{\alpha_{1_{k}}, \alpha_{2_{k}}, \ldots, \alpha_{\mid S_{k_{k}}}\right\}(k=1,2, \ldots, N)
$$

be $N$ partitions of $\boldsymbol{S}$, and $\boldsymbol{S}_{1}>\boldsymbol{S}_{2}>\ldots>\boldsymbol{S}_{N}$ be the priority relationship among $\boldsymbol{S}_{1}, \boldsymbol{S}_{2}, \ldots, \boldsymbol{S}_{N}$. If $\alpha_{i}=\alpha=$ $\left(\left[s_{a}, s_{b}\right],\left[s_{c}, s_{d}\right]\right)$ for all $i=1,2, \ldots, n$, then LIVI$F A P A\left(\alpha_{1}, \alpha_{2}, \ldots, \alpha_{n}\right)=\alpha$.

The proof of this theorem is provided in App. B.

Eq. (10) is a generalised expression of the presented LIVIFAPA operator. If $f$ is assigned specific functions, then its specific expressions can be established:

(1) If $f(t)=-\operatorname{In}(t / h)$, then $g(t)=-\operatorname{In}(1-t / h), f^{-1}(t)=$ $h \mathrm{e}^{-t}, g^{-1}(t)=h-h \mathrm{e}^{-t}$, and a specific LIVIFAPA operator based on the Algebraic t-norm and t-conorm is obtained as follow:

$$
\begin{aligned}
& \operatorname{LIVIFAPA}^{\mathrm{A}}\left(\alpha_{1}, \alpha_{2}, \ldots, \alpha_{n}\right)=
\end{aligned}
$$

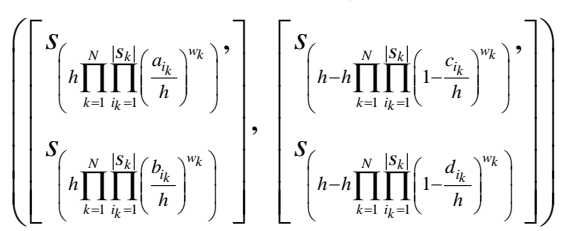

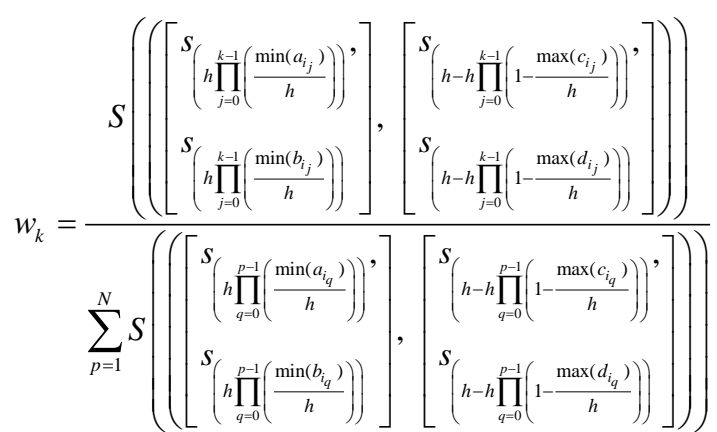

(2) If $f(t)=\operatorname{In}[(2 h-t) / t]$, then $g(t)=\operatorname{In}[(h+t) /(h-t)]$, $f^{-1}(t)=(2 h) /\left(\mathrm{e}^{t}+1\right), g^{-1}(t)=\left(h \mathrm{e}^{t}-h\right) /\left(\mathrm{e}^{t}+1\right)$, and a specific LIVIFAPA operator based on the Einstein tnorm and $\mathrm{t}$-conorm is obtained as follow:

$$
\begin{aligned}
& \text { LIVIFAPA }^{\mathrm{E}}\left(\alpha_{1}, \alpha_{2}, \ldots, \alpha_{n}\right)=
\end{aligned}
$$

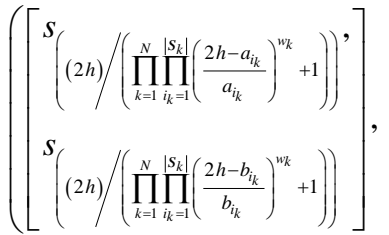

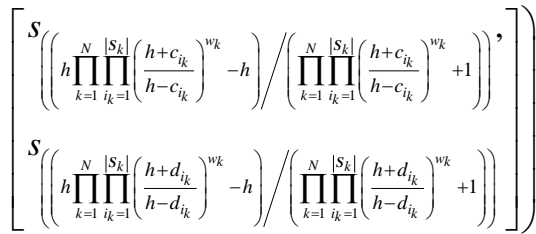

where

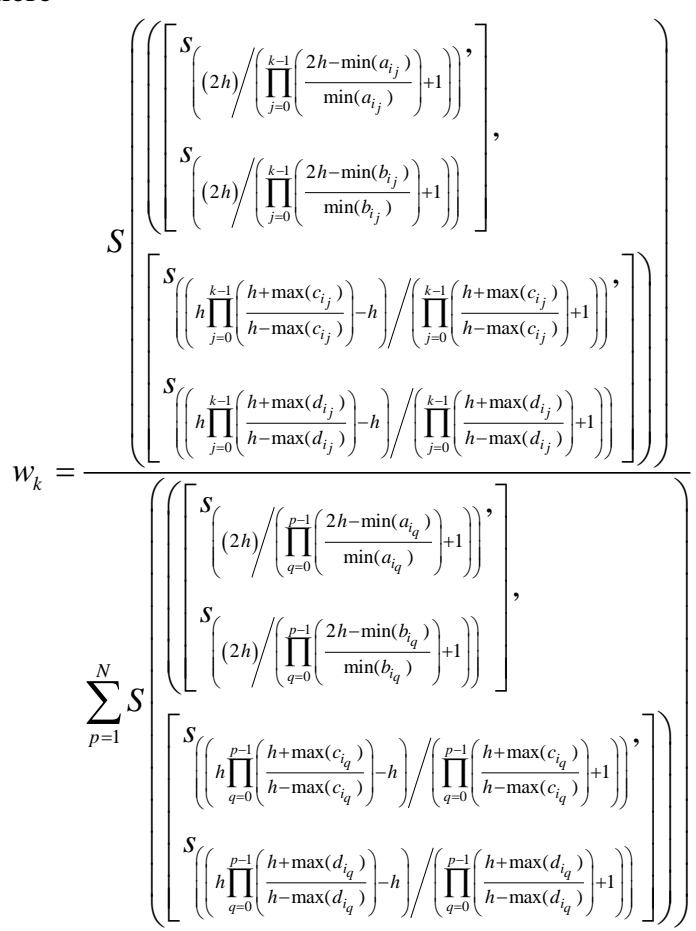


(3) If $f(t)=\operatorname{In}\{[h \lambda+(1-\lambda) t] / t\} \quad(\lambda>0)$, then $g(t)=$ $\operatorname{In}\{[h+(\lambda-1) t] /(h-t)\}, f^{-1}(t)=(\lambda h) /\left(\mathrm{e}^{t}+\lambda-1\right), g^{-1}(t)=$ $\left(h \mathrm{e}^{t}-h\right) /\left(\mathrm{e}^{t}+\lambda-1\right)$, and a specific LIVIFAPA operator based on the Hamacher t-norm and t-conorm is obtained as follow:

$$
\begin{aligned}
& \operatorname{LIVIFAPA}^{\mathbf{H}}\left(\alpha_{1}, \alpha_{2}, \ldots, \alpha_{n}\right)=
\end{aligned}
$$

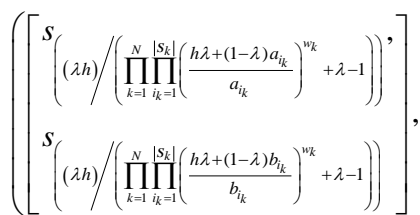

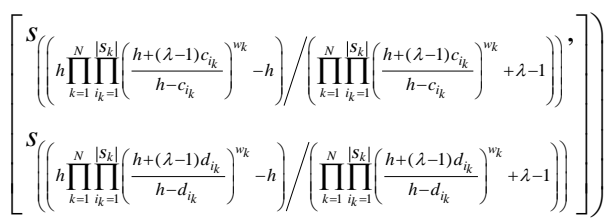

where

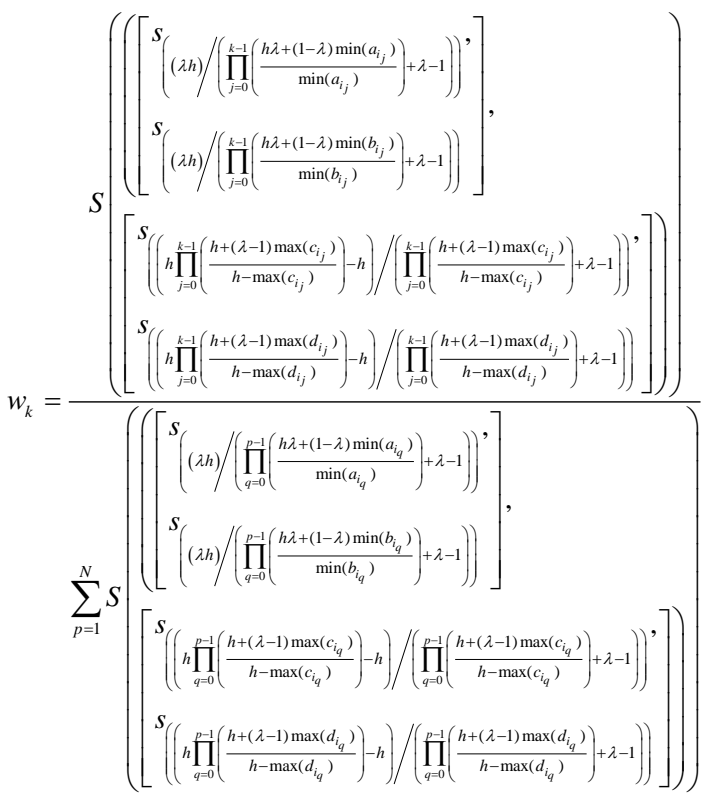

This operator will reduce to the LIVIFAPA ${ }^{\mathbf{A}}$ operator when $\lambda=1$ and will reduce to the LIVIFAPA ${ }^{\mathbf{E}}$ operator when $\lambda=2$. Therefore, the LIVIFAPA ${ }^{\mathbf{H}}$ operator is the generalised form of the LIVIFAPA ${ }^{\mathbf{A}}$ and LIVIFAPA $^{\mathbf{E}}$ operators.

(4) If $f(t)=-\operatorname{In}\left[\left(\varepsilon^{-1}\right) /\left(\varepsilon^{t / h}-1\right)\right](\varepsilon>1)$, then $g(t)=$ $-\operatorname{In}\left[\left(\varepsilon^{-1}\right) /\left(\varepsilon^{1-t / h}-1\right)\right], f^{-1}(t)=\log _{\varepsilon}\left[1+\left(\varepsilon^{-1}\right) / \mathrm{e}^{-t}\right]^{h}, g^{-1}(t)$ $=h-\log _{\varepsilon}\left[1+\left(\varepsilon^{-1}\right) / \mathrm{e}^{-t}\right]^{h}$, and a specific LIVIFAPA operator based on the Frank t-norm and t-conorm is obtained as follow:

$$
\begin{aligned}
& \operatorname{LIVIFAPA}^{\mathbf{F}}\left(\alpha_{1}, \alpha_{2}, \ldots, \alpha_{n}\right)=
\end{aligned}
$$

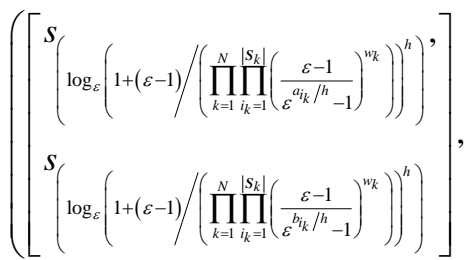

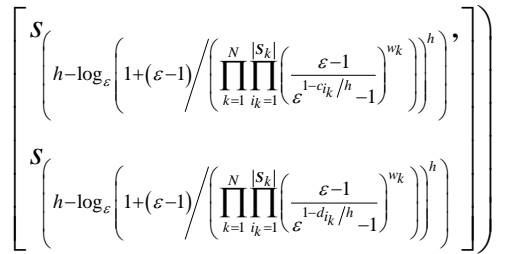

where

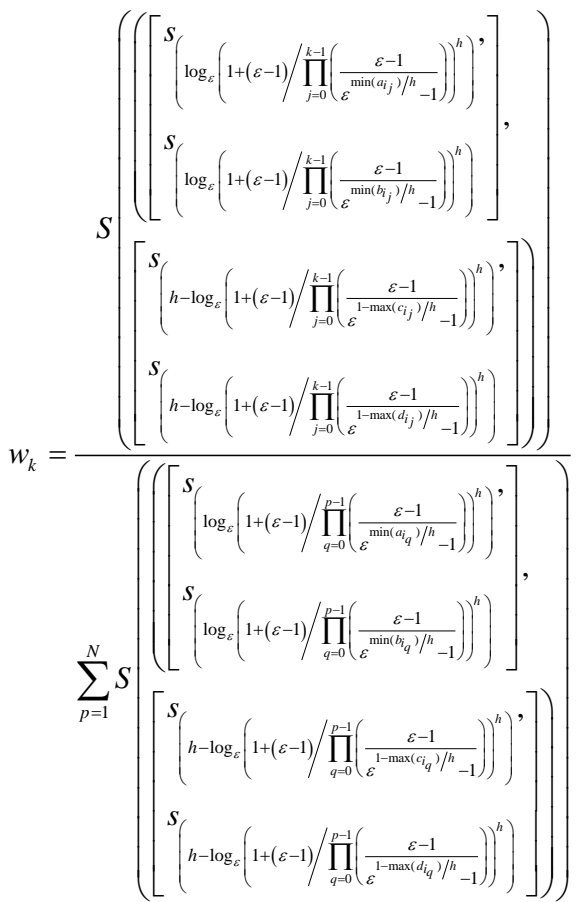

\subsection{LIVIFAPO operator}

A LIVIFAPO operator is a PO operator of LIVIFNs, in which all operations are carried out via the ATT based operational laws for LIVIFNs. The formal definition of this operator is as follow:

Definition 6. Let $\left(\alpha_{1}, \alpha_{2}, \ldots, \alpha_{n}\right)$ (where

$$
\alpha_{i}=\left(\left[s_{a_{i}}, s_{b_{i}}\right],\left[s_{c_{i}}, s_{d_{i}}\right]\right)(i=1,2, \ldots, n)
$$

) be a collection of $n$ LIVIFNs, $S=\left\{\alpha_{1}, \alpha_{2}, \ldots, \alpha_{n}\right\}$ be an ordered set of $\alpha_{1}, \alpha_{2}, \ldots, \alpha_{n}$,

$$
\boldsymbol{S}_{k}=\left\{\alpha_{1_{k}}, \alpha_{2_{k}}, \ldots, \alpha_{\left|\boldsymbol{S}_{k}\right|_{k}}\right\}(k=1,2, \ldots, N)
$$


be $N$ partitions of $\boldsymbol{S}, \boldsymbol{S}_{1}>\boldsymbol{S}_{2}>\ldots>\boldsymbol{S}_{N}$ be the priority relationship among $\boldsymbol{S}_{1}, \boldsymbol{S}_{2}, \ldots, \boldsymbol{S}_{N}, T_{0}=\left(\left[s_{h}, s_{h}\right],\left[s_{0}\right.\right.$, $\left.s_{0}\right]$ ),

$$
\begin{aligned}
& T_{k}=\left(\left[s_{\max \left(a_{i_{k}}\right)}, s_{\max \left(b_{i_{k}}\right)}\right],\left[s_{\min \left(c_{i_{k}}\right)}, s_{\min \left(d_{i_{k}}\right)}\right]\right) \\
& w_{k}=S\left(\bigotimes_{j=0}^{k-1} T_{j}\right) / \sum_{p=1}^{N} S\left(\bigotimes_{q=0}^{p-1} T_{q}\right)
\end{aligned}
$$

$\alpha_{i} \oplus \alpha_{j}(j=1,2, \ldots, n)$ be the sum operation of $\alpha_{i}$ and $\alpha_{j}$ based on ATT, and $r \alpha_{i}(r>0)$ be the multiplication operation of $\alpha_{i}$ based on ATT. Then the aggregation function

$$
\operatorname{LIVIFAPO}\left(\alpha_{1}, \alpha_{2}, \ldots, \alpha_{n}\right)=\bigoplus_{k=1 i_{k}=1}^{N}\left|S_{k}\right|
$$

is called as the LIVIFAPO operator.

According to Eq.s (3)-(6) and (15), the following theorem is obtained:

Theorem 3. Let $\left(\alpha_{1}, \alpha_{2}, \ldots, \alpha_{n}\right)$ (where

$$
\alpha_{i}=\left(\left[s_{a_{i}}, s_{b_{i}}\right],\left[s_{c_{i}}, s_{d_{i}}\right]\right)(i=1,2, \ldots, n)
$$

) be a collection of $n$ LIVIFNs, $S=\left\{\alpha_{1}, \alpha_{2}, \ldots, \alpha_{n}\right\}$ be an ordered set of $\alpha_{1}, \alpha_{2}, \ldots, \alpha_{n}$,

$$
\boldsymbol{S}_{k}=\left\{\alpha_{1_{k}}, \alpha_{2_{k}}, \ldots, \alpha_{\left|S_{k}\right|_{k}}\right\}(k=1,2, \ldots, N)
$$

be $N$ partitions of $\boldsymbol{S}$, and $\boldsymbol{S}_{1}>\boldsymbol{S}_{2}>\ldots>\boldsymbol{S}_{N}$ be the priority relationship among $\boldsymbol{S}_{1}, \boldsymbol{S}_{2}, \ldots, \boldsymbol{S}_{N}$. Then

$$
\begin{aligned}
& \operatorname{LIVIFAPO}\left(\alpha_{1}, \alpha_{2}, \ldots, \alpha_{n}\right)=
\end{aligned}
$$

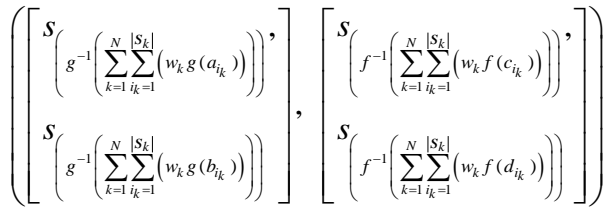

where

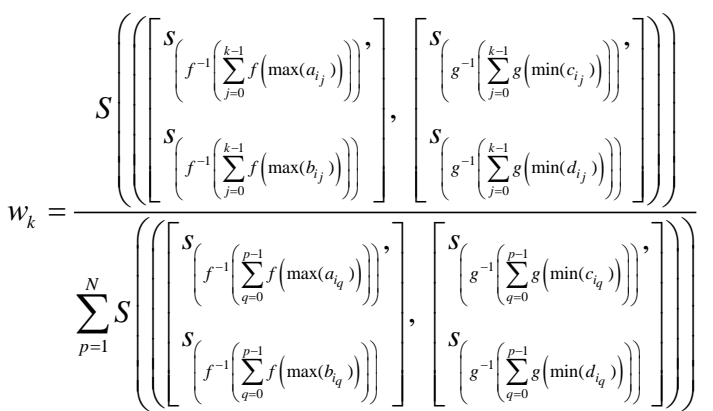

and it is still a LIVIFN.

The proof of this theorem is provided in App. C.

The LIVIFAPO operator has the following property:

Theorem 4 (Idempotency). Let $\left(\alpha_{1}, \alpha_{2}, \ldots, \alpha_{n}\right)$ (where

$$
\alpha_{i}=\left(\left[s_{a_{i}}, s_{b_{i}}\right],\left[s_{c_{i}}, s_{d_{i}}\right]\right)(i=1,2, \ldots, n)
$$

) be a collection of $n$ LIVIFNs, $S=\left\{\alpha_{1}, \alpha_{2}, \ldots, \alpha_{n}\right\}$ be an ordered set of $\alpha_{1}, \alpha_{2}, \ldots, \alpha_{n}$,

$$
\boldsymbol{S}_{k}=\left\{\alpha_{1_{k}}, \alpha_{2_{k}}, \ldots, \alpha_{\left|\boldsymbol{S}_{k}\right|_{k}}\right\}(k=1,2, \ldots, N)
$$

be $N$ partitions of $\boldsymbol{S}$, and $\boldsymbol{S}_{1}>\boldsymbol{S}_{2}>\ldots>\boldsymbol{S}_{N}$ be the priority relationship among $\boldsymbol{S}_{1}, \boldsymbol{S}_{2}, \ldots, \boldsymbol{S}_{N}$. If $\alpha_{i}=\alpha=$ $\left(\left[s_{a}, s_{b}\right],\left[s_{c}, s_{d}\right]\right)$ for all $i=1,2, \ldots, n$, then $L I V I-$ $F A P O\left(\alpha_{1}, \alpha_{2}, \ldots, \alpha_{n}\right)=\alpha$.

The proof of this theorem is provided in App. D.

Eq. (16) is a generalised expression of the presented LIVIFAPO operator. If $f$ is assigned specific functions, then its specific expressions can be established:

(1) If $f(t)=-\operatorname{In}(t / h)$, then $g(t)=-\operatorname{In}(1-t / h), f^{-1}(t)=$ $h \mathrm{e}^{-t}, g^{-1}(t)=h-h \mathrm{e}^{-t}$, and a specific LIVIFAPO operator based on the Algebraic t-norm and t-conorm is obtained as follow:

$$
\begin{aligned}
& \operatorname{LIVIFAPO}^{\mathbf{A}}\left(\alpha_{1}, \alpha_{2}, \ldots, \alpha_{n}\right)=
\end{aligned}
$$

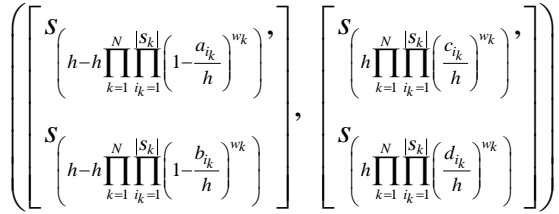

where

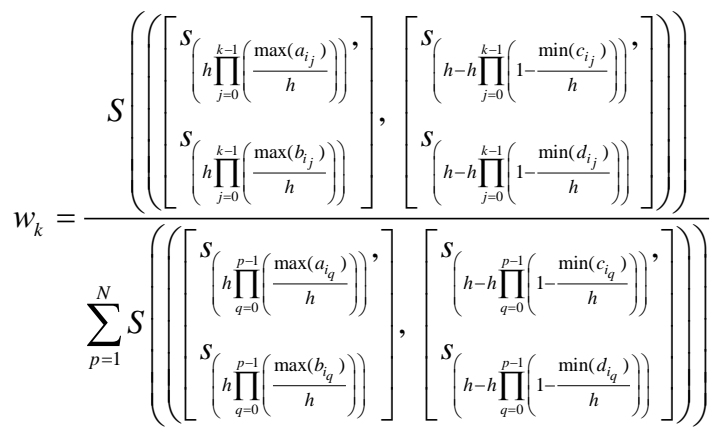

(2) If $f(t)=\operatorname{In}[(2 h-t) / t]$, then $g(t)=\operatorname{In}[(h+t) /(h-t)]$, $f^{-1}(t)=(2 h) /\left(\mathrm{e}^{t}+1\right), g^{-1}(t)=\left(h \mathrm{e}^{t}-h\right) /\left(\mathrm{e}^{t}+1\right)$, and a specific LIVIFAPO operator based on the Einstein tnorm and t-conorm is obtained as follow:

$$
\begin{aligned}
& \text { LIVIFAPO }{ }^{\mathbf{E}}\left(\alpha_{1}, \alpha_{2}, \ldots, \alpha_{n}\right)= \\
& \left(\left[\begin{array}{c}
S\left(\left(h \prod_{k=1}^{N} \prod_{i_{k}=1}^{\left|S_{k}\right|}\left(\frac{h+a_{i_{k}}}{h-a_{i_{k}}}\right)^{w_{k}}-h\right) /\left(\prod_{k=1}^{N} \prod_{i_{k}=1}^{\left|S_{k}\right|}\left(\frac{h+a_{i_{k}}}{h-a_{i_{k}}}\right)^{w_{k}}+1\right)\right), \\
S\left(\left(h \prod_{k=1}^{N} \prod_{i_{k}=1}^{\left|S_{k}\right|}\left(\frac{h+b_{i_{k}}}{h-b_{i_{k}}}\right)^{w_{k}}-h\right) /\left(\prod_{k=1}^{N} \prod_{i_{k}=1}^{\left|S_{k}\right|}\left(\frac{h+b_{i_{k}}}{h-b_{i_{k}}}\right)^{w_{k}}+1\right)\right)
\end{array}\right],\right.
\end{aligned}
$$

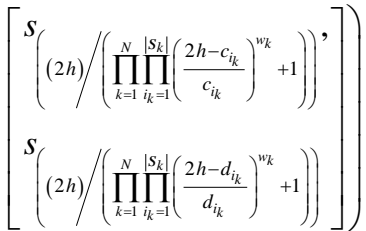


where

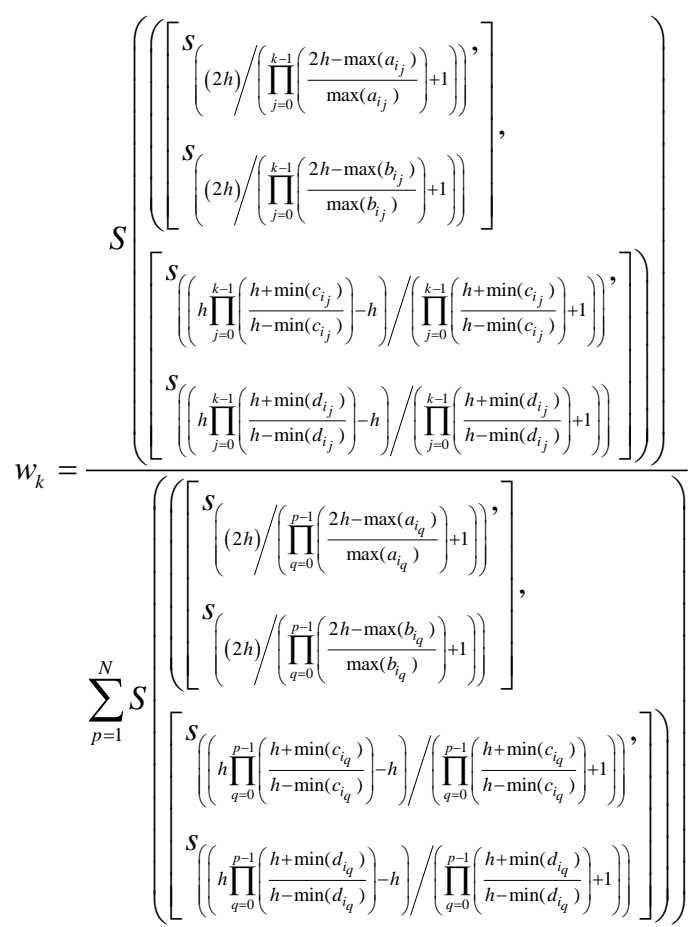

(3) If $f(t)=\operatorname{In}\{[h \lambda+(1-\lambda) t] / t\} \quad(\lambda>0)$, then $g(t)=$ $\operatorname{In}\{[h+(\lambda-1) t] /(h-t)\}, f^{-1}(t)=(\lambda h) /\left(\mathrm{e}^{t}+\lambda-1\right), g^{-1}(t)=$ $\left(h \mathrm{e}^{t}-h\right) /\left(\mathrm{e}^{t}+\lambda-1\right)$, and a specific LIVIFAPO operator based on the Hamacher t-norm and t-conorm is obtained as follow:

$$
\begin{aligned}
& \operatorname{LIVIFAPO}^{\mathbf{H}}\left(\alpha_{1}, \alpha_{2}, \ldots, \alpha_{n}\right)=
\end{aligned}
$$

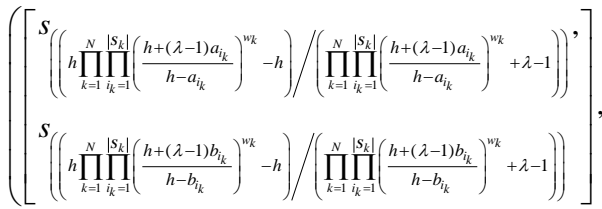

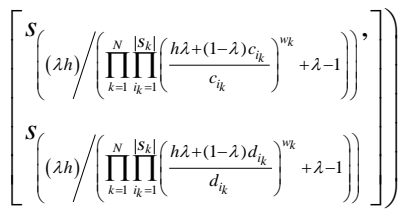

where

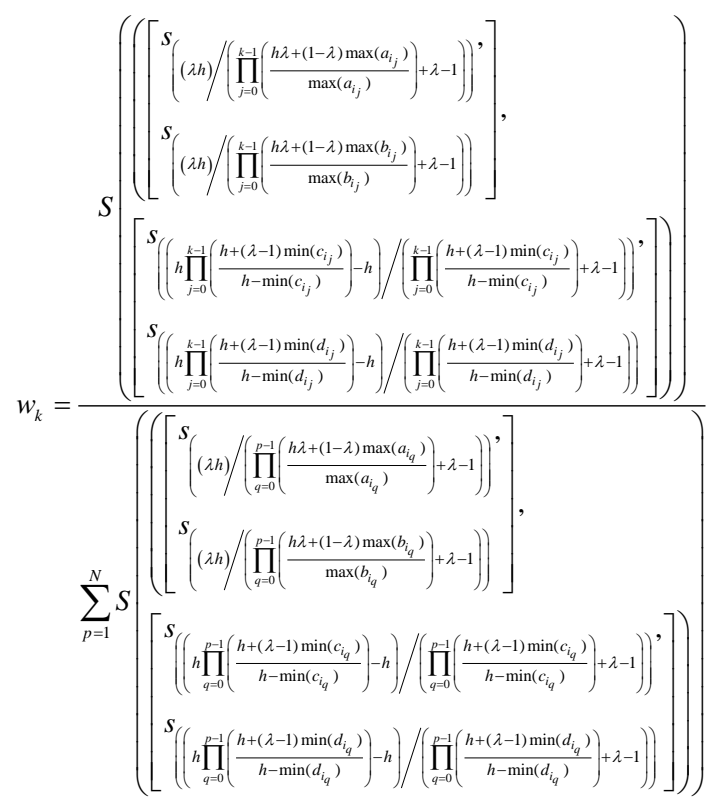

This operator will reduce to the LIVIFAPO ${ }^{\mathbf{A}}$ operator when $\lambda=1$ and will reduce to the LIVIFAPO ${ }^{\mathbf{E}}$ operator when $\lambda=2$. Therefore, the LIVIFAPO ${ }^{\mathbf{H}}$ operator is the generalised form of the LIVIFAPO ${ }^{\mathbf{A}}$ and LIVIFAPO $^{\mathbf{E}}$ operators.

(4) If $f(t)=-\operatorname{In}\left[\left(\varepsilon^{-1}\right) /\left(\varepsilon^{t / h}-1\right)\right](\varepsilon>1)$, then $g(t)=$ $-\operatorname{In}\left[\left(\varepsilon^{-1}\right) /\left(\varepsilon^{1-t / h}-1\right)\right], f^{-1}(t)=\log _{\varepsilon}\left[1+\left(\varepsilon^{-1}\right) / \mathrm{e}^{-t}\right]^{h}, g^{-1}(t)$ $=h-\log _{\varepsilon}\left[1+\left(\varepsilon^{-1}\right) / \mathrm{e}^{-t}\right]^{h}$, and a specific LIVIFAPO operator based on the Frank t-norm and t-conorm is obtained as follow:

$$
\begin{aligned}
& \operatorname{LIVIFAPO}^{\mathbf{F}}\left(\alpha_{1}, \alpha_{2}, \ldots, \alpha_{n}\right)=
\end{aligned}
$$

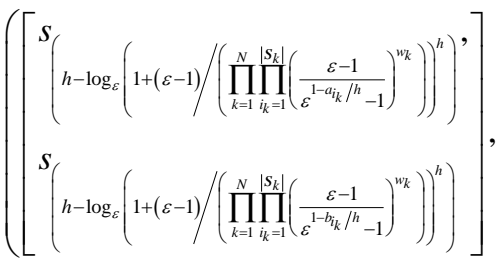

$$
\begin{aligned}
& {\left[\begin{array}{l}
\left.S_{\left(\log _{\varepsilon}(1+(\varepsilon-1)\right.}\left(\left(\prod_{k=1}^{N} \prod_{i_{k}=1}^{\left|S_{k}\right|}\left(\frac{\varepsilon-1}{\varepsilon^{c_{i k} / h}-1}\right)^{w_{k}}\right)\right)^{h}\right), \\
\left.S^{\prime}\left(\log _{\varepsilon}\left(1+(\varepsilon-1) /\left(\prod_{k=1}^{N} \prod_{i_{k}=1}^{\left|S_{k}\right|}\left(\frac{\varepsilon-1}{\varepsilon^{i_{k} / h}-1}\right)^{w_{k}}\right)\right)^{h}\right)\right]
\end{array}\right]}
\end{aligned}
$$

where 


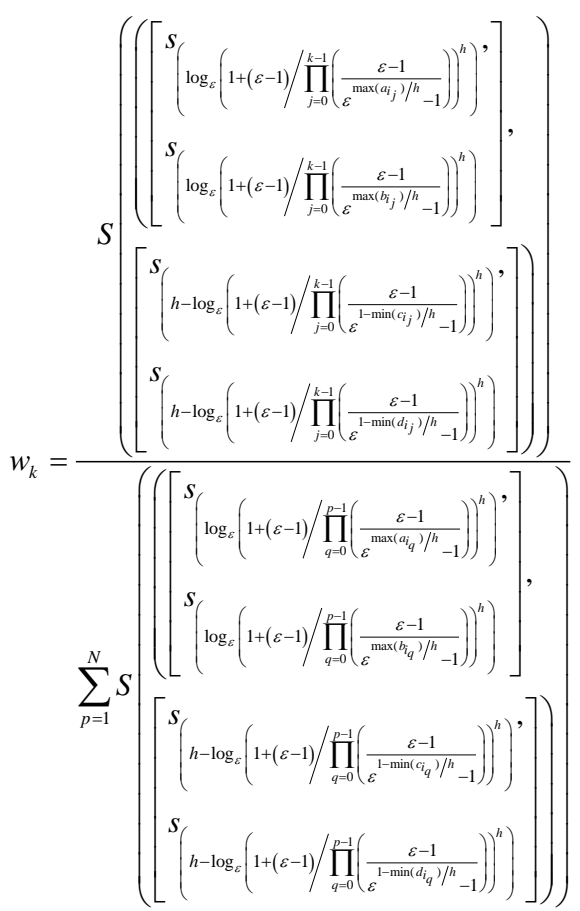

\section{MCDM method}

In this section, a MCDM method based on the presented LIVIFAPA and LIVIFAPO operators is designed to solve the MCDM problems based on LIVIFNs.

Generally, a MCDM problem based on LIVIFNs can be formalised using a set of alternatives $\boldsymbol{A}=\left\{A_{1}\right.$, $\left.A_{2}, \ldots, A_{m}\right\}$, a set of criteria $C=\left\{C_{1}, C_{2}, \ldots, C_{n}\right\}$ such that $\boldsymbol{C}$ is divided into $N$ partitions

$$
\boldsymbol{C}_{k}=\left\{C_{1_{k}}, C_{2_{k}}, \ldots, C_{\left|C_{k}\right|_{k}}\right\}(k=1,2, \ldots, N)
$$

(where all criteria in the same $\boldsymbol{C}_{k}$ have the same priority and the priority relationship among $\boldsymbol{C}_{1}, \boldsymbol{C}_{2}, \ldots$, $\boldsymbol{C}_{N}$ are $\boldsymbol{C}_{1}>\boldsymbol{C}_{2}>\ldots>\boldsymbol{C}_{N}$ ), and a linguistic intervalvalued intuitionistic fuzzy decision matrix $\boldsymbol{M}=\left[\alpha_{i, j}\right]_{m \times n}$ such that

$$
\alpha_{i, j}=\left(\left[s_{a_{i, j}}, s_{b_{i, j}}\right],\left[s_{c_{i, j}}, s_{d_{i, j}}\right]\right)
$$

is a LIVIFN which stands for the evaluation value of $C_{j}$ of $A_{i}$. On the basis of these components, the problem is formalised as: Determining the desirable alternative according to $\boldsymbol{A}, \boldsymbol{C}_{k}, \boldsymbol{C}_{1}>\boldsymbol{C}_{2}>\ldots>\boldsymbol{C}_{N}$, and $\boldsymbol{M}$. Using the presented LIVIFAPA and LIVIFAPO operators, the problem can be solved via the following steps:

(1) Normalise the matrix $\boldsymbol{M}$. There are usually two types of criteria in a MCDM problem. They are bene- fit and cost criteria, whose values have the opposite effects on decision making. To unify such effects, the values of cost criteria in $\boldsymbol{M}$ need to be normalised and a normalised matrix is obtained as follow:

$$
\boldsymbol{M}^{\prime}=\left\{\begin{array}{l}
{\left[\left(\left[s_{a_{i, j}}, s_{b_{i, j}}\right],\left[s_{c_{i, j}}, s_{d_{i, j}}\right]\right)\right]_{m \times n}, C_{\mathrm{I}}} \\
{\left[\left(\left[s_{c_{i, j}}, s_{d_{i, j}}\right],\left[s_{a_{i, j}}, s_{b_{i, j}}\right]\right)\right]_{m \times n}, C_{\mathrm{II}}}
\end{array}\right.
$$

where $C_{\mathrm{I}}$ stands for "if $C_{j}$ is a benefit criterion" and $C_{\mathrm{II}}$ stands for "if $C_{j}$ is a cost criterion".

(2) Compute the collective values of $\alpha_{i, j}$. Taking the normalised matrix $\boldsymbol{M}^{\prime}$, the $N$ partitions $\boldsymbol{C}_{k}$, and the priority relationship $\boldsymbol{C}_{1}>\boldsymbol{C}_{2}>\ldots>\boldsymbol{C}_{N}$ as input, the collective values of $\alpha_{i, j}$ are calculated via

$$
\alpha_{i}=\operatorname{LIVIFAPA}\left(\alpha_{i, 1}, \alpha_{i, 2}, \ldots, \alpha_{i, n}\right)
$$

or

$$
\alpha_{i}=\operatorname{LIVIFAPO}\left(\alpha_{i, 1}, \alpha_{i, 2}, \ldots, \alpha_{i, n}\right)
$$

where LIVIFAPA can be an arbitrary specific LIVIFAPA operator (e.g. the established operators in Eq.s (11)-(14)), and LIVIFAPO can be an arbitrary specific LIVIFAPO operator (e.g. the established operators in Eq.s (17)-(20)).

(3) Compute the score and accuracy values of $\alpha_{i}$. The score and accuracy values of $\alpha_{i}$ are calculated via Eq.s (1) and (2), respectively.

(4) Sort all $A_{i}$. All $A_{i}$ are sorted according to the calculated score and accuracy values of $\alpha_{i}$ and the comparison rules of LIVIFNs.

(5) Determine the desirable alternative. The desirable alternative is determined on the basis of the sorted result of all $A_{i}$.

\section{Example and comparison}

In this section, an example about selection of additive manufacturing machines is firstly used to illustrate the designed MCDM method. Then a comparison between the presented AOs and the existing AOs of LIVIFNs are carried out to show the characteristic and advantage of the presented AOs.

\subsection{Example}

Additive manufacturing, commonly known as 3D printing, is an emerging manufacturing technology that creates $3 \mathrm{D}$ objects via depositing materials layer by layer. The existing additive manufacturing technology can be classified into vat photopolymerisation, material jetting, binder jetting, powder bed fusion, material extrusion, directed energy deposition, and 
sheet lamination. Based on these specific technologies, more than 1200 industrial additive manufacturing machines have been developed and identified in the market so far. A debate about which machine is better than the others is trivial, because each machine has its own characteristics and targeted applications. But a study about the selection of a proper machine from a certain number of alternative machines for manufacturing an end-use product is non-trivial. The reason can be analysed from two aspects. On the one hand, the selection requires a comprehensive understanding of the configuration, functionality, performance, utilities, advantages, and shortcomings of the alternative machines and the interactions of the surface, geometrical, mechanical, and build material requirements of the product. But most users of the machines lack such understanding. It is of necessity to have an effective tool to assist the selection. On the other hand, different machines may have overlaps at functionality and utilities, which increase the difficulty of the selection.

To provide an effective tool for selection of additive manufacturing machines, many kinds of methods have been presented within academia, where MCDM methods are considered as one of the important and effective methods. This kind of methods determine the proper machines via comprehensively assessing the values of multiple criteria of all alternative machines obtained from experiments or simulations or provided by domain experts. The following is an illustrative example regarding the use of the designed MCDM methods in additive manufacturing machine selection.

Suppose a machine user needs to select a proper machine from five alternative machines, denoted as $A_{1}, A_{2}, A_{3}, A_{4}$, and $A_{5}$, to fabricate a component using a specific material. The user invited an experienced domain expert to evaluate the alternative machines on the basis of six criteria, which are the cost $\left(C_{1}\right)$ and time $\left(C_{2}\right)$ for building the component and the surface roughness $\left(C_{3}\right)$, strength $\left(C_{4}\right)$, elongation $\left(C_{5}\right)$, and hardness $\left(C_{6}\right)$ of the built component. In this evaluation, the expert was asked to use LIVIFNs. The linguistic terms for describing the values of the six criteria are extremely small $\left(s_{0}\right)$, very small $\left(s_{1}\right)$, small $\left(s_{2}\right)$, slightly small $\left(s_{3}\right)$, medium $\left(s_{4}\right)$, slightly large $\left(s_{5}\right)$, large $\left(s_{6}\right)$, very large $\left(s_{7}\right)$, and extremely large $\left(s_{8}\right)$. The evaluation result of the expert is listed in Table 1.
Table 1

The evaluation result of the domain expert

\begin{tabular}{|l|l|l|l|}
\hline Machine & Build cost & Build time & Roughness \\
\hline$A_{1}$ & $\left(\left[s_{2}, s_{3}\right],\left[s_{3}, s_{4}\right]\right)$ & $\left(\left[s_{3}, s_{3}\right],\left[s_{5}, s_{5}\right]\right)$ & $\left(\left[s_{2}, s_{4}\right],\left[s_{3}, s_{4}\right]\right)$ \\
\hline$A_{2}$ & $\left(\left[s_{2}, s_{3}\right],\left[s_{4}, s_{5}\right]\right)$ & $\left(\left[s_{3}, s_{4}\right],\left[s_{4}, s_{4}\right]\right)$ & $\left(\left[s_{3}, s_{5}\right],\left[s_{2}, s_{3}\right]\right)$ \\
\hline$A_{3}$ & $\left(\left[s_{2}, s_{4}\right],\left[s_{4}, s_{4}\right]\right)$ & $\left(\left[s_{2}, s_{3}\right],\left[s_{4}, s_{5}\right]\right)$ & $\left(\left[s_{1}, s_{1}\right],\left[s_{7}, s_{7}\right]\right)$ \\
\hline$A_{4}$ & $\left(\left[s_{3}, s_{3}\right],\left[s_{5}, s_{5}\right]\right)$ & $\left(\left[s_{4}, s_{4}\right],\left[s_{4}, s_{4}\right]\right)$ & $\left(\left[s_{4}, s_{5}\right],\left[s_{2}, s_{2}\right]\right)$ \\
\hline$A_{5}$ & $\left(\left[s_{1}, s_{1}\right],\left[s_{6}, s_{7}\right]\right)$ & $\left(\left[s_{1}, s_{1}\right],\left[s_{7}, s_{7}\right]\right)$ & $\left(\left[s_{3}, s_{4}\right],\left[s_{2}, s_{3}\right]\right)$ \\
\hline Machine & Strength & Elongation & Hardness \\
\hline$A_{1}$ & $\left(\left[s_{6}, s_{6}\right],\left[s_{1}, s_{2}\right]\right)$ & $\left(\left[s_{7}, s_{7}\right],\left[s_{1}, s_{1}\right]\right)$ & $\left(\left[s_{6}, s_{7}\right],\left[s_{1}, s_{1}\right]\right)$ \\
\hline$A_{2}$ & $\left(\left[s_{5}, s_{6}\right],\left[s_{1}, s_{2}\right]\right)$ & $\left(\left[s_{4}, s_{5}\right],\left[s_{1}, s_{1}\right]\right)$ & $\left(\left[s_{4}, s_{6}\right],\left[s_{1}, s_{2}\right]\right)$ \\
\hline$A_{3}$ & $\left(\left[s_{6}, s_{6}\right],\left[s_{1}, s_{2}\right]\right)$ & $\left(\left[s_{5}, s_{6}\right],\left[s_{1}, s_{1}\right]\right)$ & $\left(\left[s_{5}, s_{6}\right],\left[s_{1}, s_{2}\right]\right)$ \\
\hline$A_{4}$ & $\left(\left[s_{3}, s_{4}\right],\left[s_{3}, s_{4}\right]\right)$ & $\left(\left[s_{3}, s_{5}\right],\left[s_{2}, s_{3}\right]\right)$ & $\left(\left[s_{2}, s_{3}\right],\left[s_{3}, s_{4}\right]\right)$ \\
\hline$A_{5}$ & $\left(\left[s_{4}, s_{5}\right],\left[s_{1}, s_{1}\right]\right)$ & $\left(\left[s_{4}, s_{6}\right],\left[s_{1}, s_{2}\right]\right)$ & $\left(\left[s_{3}, s_{5}\right],\left[s_{1}, s_{1}\right]\right)$ \\
\hline
\end{tabular}

On the basis of the above conditions, the selection can be carried out using the designed MCDM method. Its process is as follows:

(1) Normalise the matrix $\boldsymbol{M}$. For the above example, the linguistic interval-valued intuitionistic fuzzy decision matrix is $\boldsymbol{M}=\left[\alpha_{i, j}\right]_{5 \times 6}$, where the values of $\alpha_{i, j}$ are listed in Table 1. Based on this, because build cost, build time, and surface roughness are cost criteria and strength, elongation, and hardness are benefit criteria, the matrix $\boldsymbol{M}$ is normalised as the following matrix according to Eq. (21):

$$
\begin{aligned}
\boldsymbol{M}^{\prime}= & \left.\begin{array}{llll}
\left(\left[s_{3}, s_{4}\right],\left[s_{2}, s_{3}\right]\right) & \left(\left[s_{5}, s_{5}\right],\left[s_{3}, s_{3}\right]\right) & \left(\left[s_{3}, s_{4}\right],\left[s_{2}, s_{4}\right]\right) \\
\left(\left[s_{4}, s_{5}\right],\left[s_{2}, s_{3}\right]\right) & \left(\left[s_{4}, s_{4}\right],\left[s_{3}, s_{4}\right]\right) & \left(\left[s_{2}, s_{3}\right],\left[s_{3}, s_{5}\right]\right) \\
\left(\left[s_{4}, s_{4}\right],\left[s_{2}, s_{4}\right]\right) & \left(\left[s_{4}, s_{5}\right],\left[s_{2}, s_{3}\right]\right) & \left(\left[s_{7}, s_{7}\right],\left[s_{1}, s_{1}\right]\right) \\
\left(\left[s_{5}, s_{5}\right],\left[s_{3}, s_{3}\right]\right) & \left(\left[s_{4}, s_{4}\right],\left[s_{4}, s_{4}\right]\right) & \left(\left[s_{2}, s_{2}\right],\left[s_{4}, s_{5}\right]\right) \\
\left(\left[s_{6}, s_{7}\right],\left[s_{1}, s_{1}\right]\right) & \left(\left[s_{7}, s_{7}\right],\left[s_{1}, s_{1}\right]\right) & \left(\left[s_{2}, s_{3}\right],\left[s_{3}, s_{4}\right]\right) \\
& \left(\left[s_{6}, s_{6}\right],\left[s_{1}, s_{2}\right]\right) & \left(\left[s_{7}, s_{7}\right],\left[s_{1}, s_{1}\right]\right) & \left(\left[s_{6}, s_{7}\right],\left[s_{1}, s_{1}\right]\right) \\
& \left(\left[s_{5}, s_{6}\right],\left[s_{1}, s_{2}\right]\right) & \left(\left[s_{4}, s_{5}\right],\left[s_{1}, s_{1}\right]\right) & \left(\left[s_{4}, s_{6}\right],\left[s_{1}, s_{2}\right]\right) \\
& \left(\left[s_{6}, s_{6}\right],\left[s_{1}, s_{2}\right]\right) & \left(\left[s_{5}, s_{6}\right],\left[s_{1}, s_{1}\right]\right) & \left(\left[s_{5}, s_{6}\right],\left[s_{1}, s_{2}\right]\right) \\
& \left(\left[s_{3}, s_{4}\right],\left[s_{3}, s_{4}\right]\right) & \left(\left[s_{3}, s_{5}\right],\left[s_{2}, s_{3}\right]\right) & \left(\left[s_{2}, s_{3}\right],\left[s_{3}, s_{4}\right]\right) \\
& \left(\left[s_{4}, s_{5}\right],\left[s_{1}, s_{1}\right]\right) & \left(\left[s_{4}, s_{6}\right],\left[s_{1}, s_{2}\right]\right) & \left(\left[s_{3}, s_{5}\right],\left[s_{1}, s_{1}\right]\right)
\end{array}\right]
\end{aligned}
$$

(2) Compute the collective values of $\alpha_{i, j}$. Suppose that the user firstly pursues low roughness and high strength, elongation, and hardness, and secondly pursues low build cost and short build time (i.e. $\left\{C_{3}, C_{4}\right.$, $\left.\left.C_{5}, C_{6}\right\}>\left\{C_{1}, C_{2}\right\}\right)$. According to such priority relationship and the normalised matrix $\boldsymbol{M}^{\prime}$, the collective values of $\alpha_{i, j}$ can be calculated through Eq. (22) or Eq. (23) (the most general Hamacher operators in Eq.s (13) and (19) were selected and $\lambda$ in them was set as 1). The calculated results are listed in Table 2.

Table 2

The calculated $\alpha_{i}$ when $\left\{C_{3}, C_{4}, C_{5}, C_{6}\right\}>\left\{C_{1}, C_{2}\right\}$

\begin{tabular}{|l|l|l|}
\hline$\alpha_{i}$ & LIVIFAPA $^{\mathbf{H}}$ (see Eq. $\left.(13)\right)$ & LIVIFAPO $^{\mathbf{H}}$ (see Eq. $\left.(19)\right)$ \\
\hline$\alpha_{1}$ & $\left(\left[s_{1.6042}, s_{2.3654}\right],\left[s_{4.0761}, s_{5.4442}\right]\right)$ & $\left(\left[s_{7.7621}, s_{7.8685}\right],\left[s_{0.0454}, s_{0.1150}\right]\right)$ \\
\hline$\alpha_{2}$ & $\left(\left[s_{0.5343}, s_{1.3533}\right],\left[s_{4.5393}, s_{6.2808}\right]\right)$ & $\left(\left[s_{7.0188}, s_{7.6415}\right],\left[s_{0.0492}, s_{0.1935}\right]\right)$ \\
\hline$\alpha_{3}$ & $\left(\left[s_{2.0289}, s_{2.7497}\right],\left[s_{3.3927}, s_{4.9972}\right]\right)$ & $\left(\left[s_{7.7683}, s_{7.8685}\right],\left[s_{0.0260}, s_{0.0909}\right]\right)$ \\
\hline$\alpha_{4}$ & $\left(\left[s_{0.1753}, s_{0.4294}\right],\left[s_{6.5775}, s_{7.2807}\right]\right)$ & $\left(\left[s_{6.3430}, s_{7.0676}\right],\left[s_{0.3397}, s_{0.7230}\right]\right)$ \\
\hline$\alpha_{5}$ & $\left(\left[s_{0.5169}, s_{1.5869}\right],\left[s_{3.9750}, s_{4.9041}\right]\right)$ & $\left(\left[s_{7.4679}, s_{7.8481}\right],\left[s_{0.0217}, s_{0.0381}\right]\right)$ \\
\hline
\end{tabular}


To facilitate the understanding of the working process of the presented AOs, the calculation process of $\alpha_{1}$ using the LIVIFAPA ${ }^{\mathbf{H}}$ operator and the calculation process of $\alpha_{1}$ using the LIVIFAPO ${ }^{\mathbf{H}}$ operator are taken as two illustrative examples:

a) When the LIVIFAPA ${ }^{\mathbf{H}}$ operator is selected: According to the known conditions, it can be obtained that

$$
\begin{aligned}
& \boldsymbol{S}=\left\{\alpha_{1,1}, \alpha_{1,2}, \alpha_{1,3}, \alpha_{1,4}, \alpha_{1,5}, \alpha_{1,6}\right\} \\
& \boldsymbol{S}_{1}=\left\{\alpha_{1,3}, \alpha_{1,4}, \alpha_{1,5}, \alpha_{1,6}\right\}=\left\{\left(\left[s_{3}, s_{4}\right],\left[s_{2}, s_{4}\right]\right),\right. \\
&\left(\left[s_{6}, s_{6}\right],\left[s_{1}, s_{2}\right]\right), \\
&\left(\left[s_{7}, s_{7}\right],\left[s_{1}, s_{1}\right]\right), \\
&\left.\left(\left[s_{6}, s_{7}\right],\left[s_{1}, s_{1}\right]\right)\right\} \\
& S_{2}=\left\{\alpha_{1,1}, \alpha_{1,2}\right\}=\left\{\left(\left[s_{3}, s_{4}\right],\right.\right. {\left.\left[s_{2}, s_{3}\right]\right), } \\
&\left(\left[s_{5}, s_{5}\right],\right. {\left.\left.\left[s_{3}, s_{3}\right]\right)\right\} }
\end{aligned}
$$

$\boldsymbol{S}_{1}>\boldsymbol{S}_{2}$, and $T_{0}=\left(\left[s_{8}, s_{8}\right],\left[s_{0}, s_{0}\right]\right)$. Then $T_{1}$ is computed as follow:

$T_{1}=\left(\left[s_{3}, s_{4}\right],\left[s_{2}, s_{4}\right]\right)$

Based on this, the priority weights are calculated as $w_{1}=0.6531$ and $w_{2}=0.3469$. Then the aggregation result of $\left(\alpha_{1,1}, \alpha_{1,2}, \ldots, \alpha_{1,6}\right)$ can be expressed as:

$$
\begin{aligned}
& \text { IIVIFAPA }^{\mathbf{H}}\left(\alpha_{1,1}, \alpha_{1,2}, \ldots, \alpha_{1,6}\right)= \\
& \left(\alpha_{1,3}^{w_{1}} \otimes \alpha_{1,4}^{w_{1}} \otimes \alpha_{1,5}^{w_{1}} \otimes \alpha_{1,6}^{w_{1}}\right) \otimes\left(\alpha_{1,1}^{w_{2}} \otimes \alpha_{1,2}^{w_{2}}\right)
\end{aligned}
$$

According to the operational laws in Eq.s (4) and (6), $f(t)=\operatorname{In}\{[h \lambda+(1-\lambda) t] / t\} \quad(\lambda=1), g(t)=\operatorname{In}\{[h+(\lambda-1) t] /$ $(h-t)\}, f^{-1}(t)=(\lambda h) /\left(\mathrm{e}^{t}+\lambda-1\right)$, and $g^{-1}(t)=\left(h \mathrm{e}^{t-h}\right) /\left(\mathrm{e}^{t}+\right.$ $\lambda-1)$, the value of $\alpha_{1}$ is computed as:

$\alpha_{1}=\left\{\left(\left[s_{1.6042}, s_{2.3654}\right],\left[s_{4.0761}, s_{5.4442}\right]\right)\right\}$

b) When the LIVIFAPO ${ }^{\mathbf{H}}$ operator is selected: According to the known conditions, it can be obtained that

$$
\begin{aligned}
& \boldsymbol{S}=\left\{\alpha_{1,1}, \alpha_{1,2}, \alpha_{1,3}, \alpha_{1,4}, \alpha_{1,5}, \alpha_{1,6}\right\} \\
& \boldsymbol{S}_{1}=\left\{\alpha_{1,3}, \alpha_{1,4}, \alpha_{1,5}, \alpha_{1,6}\right\}=\left\{\left(\left[s_{3}, s_{4}\right],\left[s_{2}, s_{4}\right]\right)\right. \text {, } \\
& \left(\left[s_{6}, s_{6}\right],\left[s_{1}, s_{2}\right]\right), \\
& \left(\left[s_{7}, s_{7}\right],\left[s_{1}, s_{1}\right]\right) \text {, } \\
& \left.\left(\left[s_{6}, s_{7}\right],\left[s_{1}, s_{1}\right]\right)\right\} \\
& \boldsymbol{S}_{2}=\left\{\alpha_{1,1}, \alpha_{1,2}\right\}=\left\{\left(\left[s_{3}, s_{4}\right],\left[s_{2}, s_{3}\right]\right),\right. \\
& \left.\left(\left[s_{5}, s_{5}\right],\left[s_{3}, s_{3}\right]\right)\right\}
\end{aligned}
$$

$\boldsymbol{S}_{1}>\boldsymbol{S}_{2}$, and $T_{0}=\left(\left[s_{8}, s_{8}\right],\left[s_{0}, s_{0}\right]\right)$. Then $T_{1}$ is computed as follow:

$$
T_{1}=\left(\left[s_{7}, s_{7}\right],\left[s_{1}, s_{1}\right]\right)
$$

Based on this, the priority weights are calculated as $w_{1}=0.5333$ and $w_{2}=0.4667$. Then the aggregation result of $\left(\alpha_{1,1}, \alpha_{1,2}, \ldots, \alpha_{1,6}\right)$ can be expressed as:

$$
\begin{aligned}
& \text { IIVIFAPO }^{\mathbf{H}}\left(\alpha_{1,1}, \alpha_{1,2}, \ldots, \alpha_{1,6}\right)= \\
& \left(w_{1} \alpha_{1,3} \oplus w_{1} \alpha_{1,4} \oplus w_{1} \alpha_{1,5} \oplus w_{1} \alpha_{1,6}\right) \oplus\left(w_{2} \alpha_{1,1} \oplus w_{2} \alpha_{1,2}\right)
\end{aligned}
$$

According to the operational laws in Eq.s (3) and (5), $f(t)=\operatorname{In}\{[h \lambda+(1-\lambda) t] / t\} \quad(\lambda=1), g(t)=\operatorname{In}\{[h+(\lambda-1) t] /$ $(h-t)\}, f^{-1}(t)=(\lambda h) /\left(\mathrm{e}^{t}+\lambda-1\right)$, and $g^{-1}(t)=\left(h \mathrm{e}^{t-h}\right) /\left(\mathrm{e}^{t}+\right.$ $\lambda-1)$, the value of $\alpha_{1}$ is computed as: $\alpha_{1}=\left\{\left(\left[s_{7.7621}, s_{7.8685}\right],\left[s_{0.0454}, s_{0.1150}\right]\right)\right\}$

(3) Compute the score and accuracy values of $\alpha_{i}$. According to Eq.s (1) and (2), the score and accuracy values of $\alpha_{i}$ can be calculated. The calculated results are shown in Table 3.

Table 3

The calculated $S\left(\alpha_{i}\right)$ and $A\left(\alpha_{i}\right)$ when $\left\{C_{3}, C_{4}, C_{5}, C_{6}\right\}>\left\{C_{1}, C_{2}\right\}$

\begin{tabular}{|l|l|l|l|l|}
\hline \multirow{2}{*}{$\alpha_{i}$} & \multicolumn{2}{|l|}{ LIVIFAPA $^{\mathbf{H}}$ (see Eq. (13)) } & \multicolumn{2}{|l|}{ LIVIFAPO $^{\mathbf{H}}$ (see Eq. (19)) } \\
\cline { 2 - 5 } & Score & Accuracy & Score & Accuracy \\
\hline$\alpha_{1}$ & 2.6123 & 6.7449 & 7.8676 & 7.8955 \\
\hline$\alpha_{2}$ & 1.7669 & 6.3539 & 7.6044 & 7.4515 \\
\hline$\alpha_{3}$ & 3.0972 & 6.5842 & 7.8800 & 7.8768 \\
\hline$\alpha_{4}$ & 0.6866 & 7.2314 & 7.0870 & 7.2366 \\
\hline$\alpha_{5}$ & 2.3062 & 5.4915 & 7.8141 & 7.6880 \\
\hline
\end{tabular}

(4) Sort all $A_{i}$. According to Table 3 and the comparison rules of LIVIFNs, the sorted result of all $A_{i}$ of the LIVIFAPA ${ }^{\mathbf{H}}$ operator and the sorted result of all $A_{i}$ of the LIVIFAPO ${ }^{\mathbf{H}}$ operator are both $A_{3}>A_{1}>A_{5}$ $>A_{2}>A_{4}$.

(5) Determine the desirable alternative. On the basis of the above ranking, the proper additive manufacturing machine under $\left\{C_{3}, C_{4}, C_{5}, C_{6}\right\}>\left\{C_{1}, C_{2}\right\}$ is determined as $A_{3}$.

In the calculation of the collective values of $\alpha_{i, j}$, if it is assumed that the user firstly pursues low build cost and short build time, then pursues low roughness, and finally pursues high strength, elongation, and hardness (i.e. $\left\{C_{1}, C_{2}\right\}>\left\{C_{3}\right\}>\left\{C_{4}, C_{5}, C_{6}\right\}$ ), then the collective values of $\alpha_{i, j}$ can are calculated via Eq. (22) or Eq. (23) (the most general Hamacher operators in Eq.s (13) and (19) were selected and $\lambda$ in them was set as 1) according to this priority relationship and the normalised matrix $\boldsymbol{M}^{\prime}$, The calculated results are listed in Table 4.

Table 4

The calculated $\alpha_{i}$ when $\left\{C_{1}, C_{2}\right\}>\left\{C_{3}\right\}>\left\{C_{4}, C_{5}, C_{6}\right\}$

\begin{tabular}{|l|l|l|}
\hline$\alpha_{i}$ & LIVIFAPA $^{\mathbf{H}}($ see Eq. $(13))$ & LIVIFAPO $^{\mathbf{H}}($ see Eq. \\
\hline$\alpha_{1}$ & $\left(\left[s_{2.4221}, s_{3.1610}\right],\left[s_{3.4461}, s_{4.4277}\right]\right)$ & $\left(\left[s_{6.5844}, s_{6.9577}\right],\left[s_{0.5211}, s_{0.9034}\right]\right)$ \\
\hline$\alpha_{2}$ & $\left(\left[s_{1.8842}, s_{2.6817}\right],\left[s_{3.7188}, s_{5.2012}\right]\right)$ & $\left(\left[s_{5.4944}, s_{6.3325}\right],\left[s_{0.6885}, s_{1.4290}\right]\right)$ \\
\hline$\alpha_{3}$ & $\left(\left[s_{2.9274}, s_{3.5610}\right],\left[s_{2.7043}, s_{4.3050}\right]\right)$ & $\left(\left[s_{7.0003}, s_{7.2860}\right],\left[s_{0.2550}, s_{0.5996}\right]\right)$ \\
\hline$\alpha_{4}$ & $\left(\left[s_{1.8682}, s_{2.1143}\right],\left[s_{5.1417}, s_{5.5415}\right]\right)$ & $\left(\left[s_{5.4693}, s_{5.7261}\right],\left[s_{1.7215}, s_{2.0824}\right]\right)$ \\
\hline$\alpha_{5}$ & $\left(\left[s_{2.6178}, s_{3.9693}\right],\left[s_{2.4564}, s_{3.0384}\right]\right)$ & $\left(\left[s_{6.8745}, s_{7.4009}\right],\left[s_{0.3011}, s_{0.3786}\right]\right)$ \\
\hline
\end{tabular}

On the basis of Table 4, the score and accuracy values of $\alpha_{i}$ are calculated and shown in Table 5. 
Table 5

The calculated $S\left(\alpha_{i}\right)$ and $A\left(\alpha_{i}\right)$ when $\left\{C_{1}, C_{2}\right\}>\left\{C_{3}\right\}>\left\{C_{4}, C_{5}, C_{6}\right\}$

\begin{tabular}{|l|l|l|l|l|}
\hline \multirow{2}{*}{$\alpha_{i}$} & \multicolumn{2}{|l|}{ LIVIFAPA $^{\mathbf{H}}$ (see Eq. (13)) } & \multicolumn{2}{l|}{ LIVIFAPO $^{\mathbf{H}}$ (see Eq. (19)) } \\
\cline { 2 - 5 } & Score & Accuracy & Score & Accuracy \\
\hline$\alpha_{1}$ & 3.4273 & 6.7285 & 7.0294 & 7.4833 \\
\hline$\alpha_{2}$ & 2.9115 & 6.7430 & 6.4274 & 6.9722 \\
\hline$\alpha_{3}$ & 3.8698 & 6.7488 & 7.3579 & 7.5705 \\
\hline$\alpha_{4}$ & 2.3248 & 7.3328 & 5.8479 & 7.4996 \\
\hline$\alpha_{5}$ & 4.2731 & 6.0410 & 7.3989 & 7.4775 \\
\hline
\end{tabular}

Then, it can be obtained that the sorted result of all $A_{i}$ of the LIVIFAPA ${ }^{\mathbf{H}}$ operator and the sorted result of all $A_{i}$ of the LIVIFAPO ${ }^{\mathrm{H}}$ operator are both $A_{5}>A_{3}$ $>A_{1}>A_{2}>A_{4}$. The proper machine under $\left\{C_{1}, C_{2}\right\}$ $>\left\{C_{3}\right\}>\left\{C_{4}, C_{5}, C_{6}\right\}$ is determined as $A_{5}$.

Similarly, if it is assumed that the user firstly pursues low roughness, then pursues low build cost and short build time, and finally pursues high strength, elongation, and hardness (i.e. $\left\{C_{3}\right\}>\left\{C_{1}, C_{2}\right\}>\left\{C_{4}\right.$, $\left.\left.C_{5}, C_{6}\right\}\right)$, then the collective values of $\alpha_{i, j}$ and the score and accuracy values of $\alpha_{i}$ can also be calculated via the same equations (the most general Hamacher operators in Eq.s (13) and (19) were also selected and $\lambda$ in them was also set as 1$)$, which are respectively shown in Table 6 and Table 7.

Table 6

The calculated $\alpha_{i}$ when $\left\{C_{3}\right\}>\left\{C_{1}, C_{2}\right\}>\left\{C_{4}, C_{5}, C_{6}\right\}$

\begin{tabular}{|l|l|l|}
\hline$\alpha_{i}$ & LIVIFAPA $^{\mathbf{H}}$ (see Eq. $\left.(13)\right)$ & LIVIFAPO $^{\mathbf{H}}$ (see Eq. $\left.(19)\right)$ \\
\hline$\alpha_{1}$ & $\left(\left[s_{2.7330}, s_{3.5667}\right],\left[s_{2.8616}, s_{4.1938}\right]\right)$ & $\left(\left[s_{6.3386}, s_{6.7835}\right],\left[s_{0.6082}, s_{1.1218}\right]\right)$ \\
\hline$\alpha_{2}$ & $\left(\left[s_{1.8756}, s_{2.8415}\right],\left[s_{3.3018}, s_{5.0248}\right]\right)$ & $\left(\left[s_{4.6983}, s_{5.7851}\right],\left[s_{0.9291}, s_{1.8602}\right]\right)$ \\
\hline$\alpha_{3}$ & $\left(\left[s_{3.5090}, s_{4.1109}\right],\left[s_{2.3759}, s_{3.7552}\right]\right)$ & $\left(\left[s_{7.0354}, s_{7.2761}\right],\left[s_{0.3044}, s_{0.6190}\right]\right)$ \\
\hline$\alpha_{4}$ & $\left(\left[s_{1.6842}, s_{1.9306}\right],\left[s_{4.6159}, s_{5.3936}\right]\right)$ & $\left(\left[s_{4.1177}, s_{4.5783}\right],\left[s_{2.2345}, s_{2.9517}\right]\right)$ \\
\hline$\alpha_{5}$ & $\left(\left[s_{2.0610}, s_{3.3866}\right],\left[s_{2.6730}, s_{3.4379}\right]\right)$ & $\left(\left[s_{5.9902}, s_{6.8752}\right],\left[s_{0.4626}, s_{0.6268}\right]\right)$ \\
\hline
\end{tabular}

Table 7

The calculated $S\left(\alpha_{i}\right)$ and $A\left(\alpha_{i}\right)$ when $\left\{C_{3}\right\}>\left\{C_{1}, C_{2}\right\}>\left\{C_{4}, C_{5}, C_{6}\right\}$

\begin{tabular}{|l|l|l|l|l|}
\hline \multirow{2}{*}{$\alpha_{i}$} & \multicolumn{2}{|l|}{ LIVIFAPA $^{\mathbf{H}}$ (see Eq. (13)) } & \multicolumn{2}{l|}{ LIVIFAPO $^{\mathbf{H}}$ (see Eq. (19)) } \\
\cline { 2 - 5 } & Score & Accuracy & Score & Accuracy \\
\hline$\alpha_{1}$ & 3.8111 & 6.6776 & 6.8480 & 7.4261 \\
\hline$\alpha_{2}$ & 3.0976 & 6.5218 & 5.9235 & 6.6363 \\
\hline$\alpha_{3}$ & 4.3722 & 6.8755 & 7.3470 & 7.6174 \\
\hline$\alpha_{4}$ & 2.4013 & 6.8122 & 4.8774 & 6.9411 \\
\hline$\alpha_{5}$ & 3.8342 & 5.7792 & 6.9440 & 6.9774 \\
\hline
\end{tabular}

Then, it can be obtained that the sorted result of all $A_{i}$ of the LIVIFAPA ${ }^{\mathbf{H}}$ operator and the sorted result of all $A_{i}$ of the LIVIFAPO ${ }^{\mathrm{H}}$ operator are both $A_{3}>A_{5}$ $>A_{1}>A_{2}>A_{4}$. The proper machine under $\left\{C_{3}\right\}>$ $\left\{C_{1}, C_{2}\right\}>\left\{C_{4}, C_{5}, C_{6}\right\}$ is determined as $A_{3}$.

The ranking and selection results under the above three priority relationships are summarised in Table 8 .
Table 8

The ranking and selection results under three priority relationships

\begin{tabular}{|l|l|l|}
\hline Priority relationship & Ranking result & SR \\
\hline$\left\{C_{3}, C_{4}, C_{5}, C_{6}\right\}>\left\{C_{1}, C_{2}\right\}$ & $A_{3}>A_{1}>A_{5}>A_{2}>A_{4}$ & $A_{3}$ \\
\hline$\left\{C_{1}, C_{2}\right\}>\left\{C_{3}\right\}>\left\{C_{4}, C_{5}, C_{6}\right\}$ & $A_{5}>A_{3}>A_{1}>A_{2}>A_{4}$ & $A_{5}$ \\
\hline$\left\{C_{3}\right\}>\left\{C_{1}, C_{2}\right\}>\left\{C_{4}, C_{5}, C_{6}\right\}$ & $A_{3}>A_{5}>A_{1}>A_{2}>A_{4}$ & $A_{3}$ \\
\hline
\end{tabular}

Note: SR stands for selection result

In actual additive manufacturing machine selection, if the evaluation result in Table 1 and the three priority relationships in Table 8 are given. It is not difficult to judge that the desirable machines under these priority relationships are respectively machines $A_{3}, A_{5}$, and $A_{3}$, which exactly match the results of designed MCDM method. This demonstrate the feasibility and effectiveness of the method.

\subsection{Comparison}

As mentioned in the introduction, representative MCDM methods based on AOs of LIVIFNs are the methods presented by Liu and Qin [7], Garg and Kumar [8], and Kumar and Garg [10]. In this subsection, a comparison of the characteristics of these methods and the designed MCDM method is reported to show the advantage of the designed method.

This comparison is carried out by comparing the characteristics of the different AOs of LIVIFNs presented in different methods. In the method of Liu and Qin, the WMSM operator was presented. The method of Garg and Kumar presented the WA, OWA, HA, WG, OWG, and $\mathrm{HG}$ operators. The method of $\mathrm{Ku}-$ mar and Garg presented the PWA, POWA, PWG, and POWG operators. In the designed method, the LIVIFAPA and LIVIFAPO operators are presented. For these thirteen AOs, the capability to deal with the case in which all criteria are independent of each other and criterion weights are known, the capability to capture the interrelated relationship among criteria under known criterion weights, the capability to capture the priority relationship among criteria under unknown criterion weights, and the generality and flexibility in the aggregation of criterion information are selected as the comparison characteristics. The result of the comparison is shown in Table 9. It is explained as follows:

(1) Independent relationship. Among the thirteen AOs, the WA, OWA, HA, WG, OWG, and HG operators are suitable for the situation in which all criteria are mutually independent and the weights of criteria are known. The WMSM operator is also applicable for this situation because it can reduce to the WA operator when the parameter for specifying the inter- 
related relationship of criteria in this operator is assigned one.

(2) Interrelated relationship. The WMSM operator can capture the interrelated relationship between any two criteria when the parameter is assigned two, and can deal with the interrelated relationship among any multiple criteria when the parameter is assigned three or more.

(3) Priority relationship. Among the thirteen AOs, the PWA, POWA, PWG, and POWG operators and the presented LIVIFAPA and LIVIFAPO operators can be applied to the situation where the criteria have priority relationship and their weights are unknown.

(4) Generality and flexibility. The operations in the aggregation of criterion information in the presented LIVIFAPA and LIVIFAPO operators can be carried out using any families of ATT. Therefore, the generality and flexibility of these operators in aggregating criterion information are desirable. The operations in the remaining AOs are performed based on the Algebraic T-norm and T-conorm, one of the many families of ATT. Their generality and flexibility are relatively limited.

Table 9

The result of the comparison of different MCDM methods

\begin{tabular}{|l|l|l|l|l|}
\hline $\begin{array}{l}\text { Aggregation } \\
\text { operator }\end{array}$ & $\begin{array}{l}\text { Independent } \\
\text { relationship }\end{array}$ & $\begin{array}{l}\text { Interrelated } \\
\text { relationship }\end{array}$ & $\begin{array}{l}\text { Priority } \\
\text { relationship }\end{array}$ & $\begin{array}{l}\text { Generality, } \\
\text { flexibility }\end{array}$ \\
\hline WMSM [7] & Yes & Yes & No & Limited \\
\hline WA [8] & Yes & No & No & Limited \\
\hline OWA [8] & Yes & No & No & Limited \\
\hline HA [8] & Yes & No & No & Limited \\
\hline WG [8] & Yes & No & No & Limited \\
\hline OWG [8] & Yes & No & No & Limited \\
\hline HG [8] & Yes & No & No & Limited \\
\hline PWA [10] & No & No & Yes & Limited \\
\hline POWA [10] & No & No & Yes & Limited \\
\hline PWG [10] & No & No & Yes & Limited \\
\hline POWG [10] & No & No & Yes & Limited \\
\hline LIVIFAPA & No & No & Yes & Satisfying \\
\hline LIVIFAPO & No & No & Yes & Satisfying \\
\hline
\end{tabular}

As can be summarised from the comparison, there is not an existing MCDM method based on the AOs of LIVIFNs that can deal with the priority relationship among criteria and concurrently provide satisfying generality and flexibility in aggregating criterion information. The proposed MCDM method can make up for the shortcoming of these methods in this respect.

\section{Conclusion}

In this paper, a LIVIFAPA operator and a LIVIFAPO operator are presented to resolve the LIVIFNs based MCDM problems. The formal definitions and generalised expressions of the two operators are provided. Their properties are explored and specific expressions are established via the operational laws of LIVIFNs based on the Algebraic, Einstein, Hamacher, and Frank t-norms and t-conorms. Based on the specific expressions, a new method for solving the LIVIFNs based MCDM problems is proposed. The paper also reports an illustration of the proposed method via an additive manufacturing machine selection example and an evaluation of the method by a comparison with the existing methods.

The major contribution of the paper is the development of the LIVIFAPA and LIVIFAPO operators for solving the MCDM problems based on LIVIFNs. Compared to the existing AOs of LIVIFNs, the developed AOs have the capability to capture the priority relationship of criteria with unknown criterion weights while also provide desirable generality and flexibility in the aggregation of criterion information.

A main limitation of the developed AOs is that the AOs do not have the capabilities to reduce the negative influence of unreasonable criterion values on the aggregation results and to capture the risk attitudes of decision makers. Future work will aim especially at addressing this limitation. Further, the application of the developed AOs in practical MCDM problems in manufacturing domain may also be studied.

\section{Acknowledgements}

The authors would like to appreciate the insightful comments and suggestions from the two anonymous reviewers for the improvement of the paper. The authors also would like to acknowledge the financial supports by the EPSRC UKRI Innovation Fellowship (Ref. EP/S001328/1).

\section{Appendixes}

\section{A. Proof of Theorem 1}

Proof: According to the operational law in Eq. (4), we have

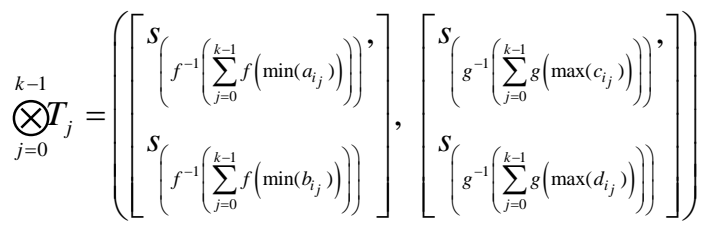




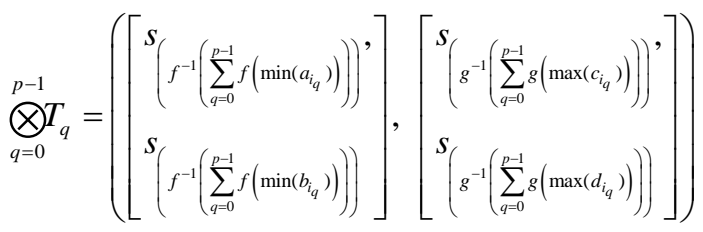

Therefore, we can obtain

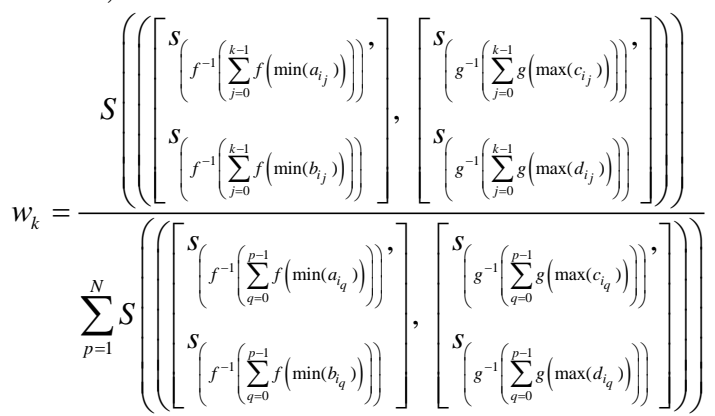

According to the operational law in Eq. (6), we have

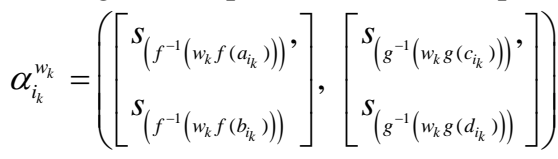

According to the operational law in Eq. (4), we can obtain

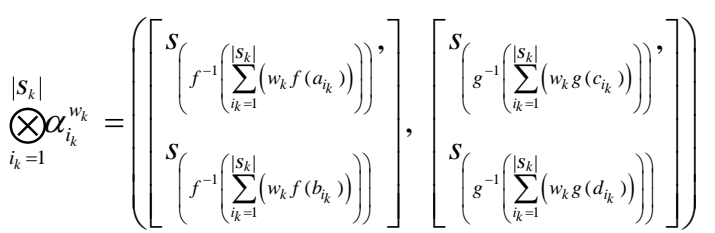

${ }_{N}\left|S_{k}\right|$

$$
\bigotimes_{k=1 i_{k}=1}^{N} \alpha_{i_{k}}^{w_{k}}=
$$

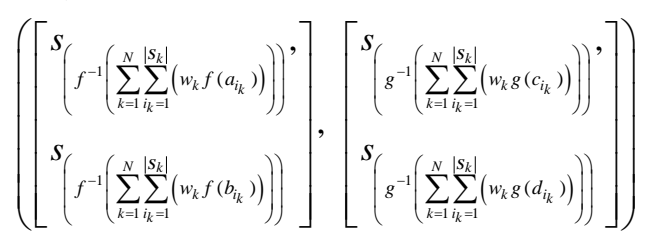

which complete the proof of the theorem.

\section{B. Proof of Theorem 2}

Proof: According to Theorem 1, we have

$$
\operatorname{LIVIFAPA}\left(\alpha_{1}, \alpha_{2}, \ldots, \alpha_{n}\right)=
$$

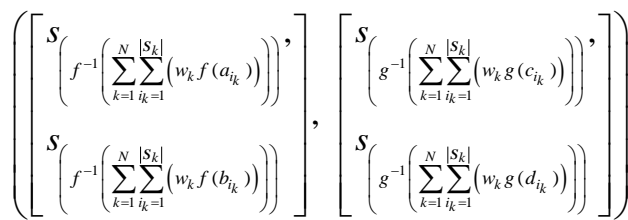

where

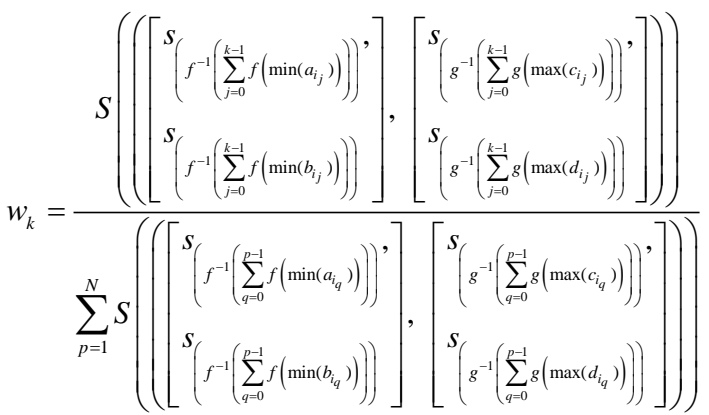

Because $\alpha_{i}=\alpha=\left(\left[s_{a}, s_{b}\right],\left[s_{c}, s_{d}\right]\right)$ for all $i=1,2, \ldots, n$, we can obtain

$$
\begin{aligned}
& S_{\left(f^{-1}\left(\sum_{k=1}^{N} \sum_{i_{k}=1}^{S}\left(w_{k} f\left(a_{i_{k}}\right)\right)\right)\right)}=s_{\left(f^{-1}\left(\left(\sum_{k=1}^{N} w_{k}\right) f(a)\right)\right)}=s_{\left(f^{-1}(f(a))\right)}=s_{a} \\
& s\left(f^{-1}\left(\sum_{k=1}^{N} \sum_{k_{k}=1}^{\left|S_{k}\right|}\left(w_{k} f\left(b_{k_{k}}\right)\right)\right)\right)=s_{\left(f^{-1}\left(\left(\sum_{k=1}^{N} w_{k}\right) f(b)\right)\right)}=s_{\left(f^{-1}(f(b))\right)}=s_{b} \\
& S_{\left(g^{-1}\left(\sum_{k=1}^{N} \sum_{k=1}\left(S_{k}\left(w_{k} g\left(c_{k_{k}}\right)\right)\right)\right)\right.}=S_{\left(g^{-1}\left(\left(\sum_{k=1}^{N} w_{k}\right) g(c)\right)\right)}=S_{\left(g^{-1}(g(c))\right)}=S_{c} \\
& s_{\left(g^{-1}\left(\sum_{k=1}^{N} \sum_{k=1}^{S_{k}}\left(w_{k} g\left(d_{k^{\prime}}\right)\right)\right)\right)}=s_{\left(g^{-1}\left(\left(\sum_{k=1}^{N} w_{k}\right) g(d)\right)\right)}=s_{\left(g^{-1}(g(d))\right)}=s_{d}
\end{aligned}
$$

Therefore, we have LIVIFAPA $\left(\alpha_{1}, \alpha_{2}, \ldots, \alpha_{n}\right)=\left(\left[s_{a}\right.\right.$, $\left.\left.s_{b}\right],\left[s_{c}, s_{d}\right]\right)$. This completes the proof of the theorem.

\section{Proof of Theorem 3}

Proof: According to the operational law in Eq. (4), we have

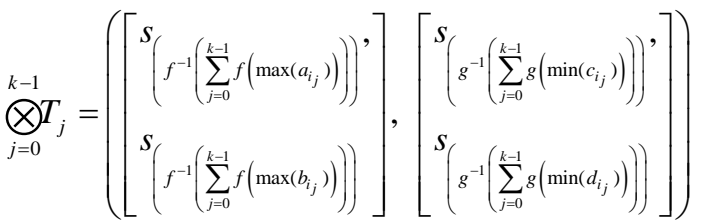

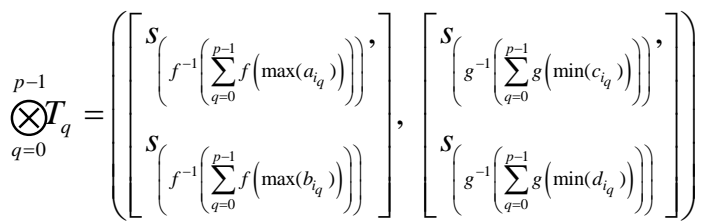

Therefore, we can obtain

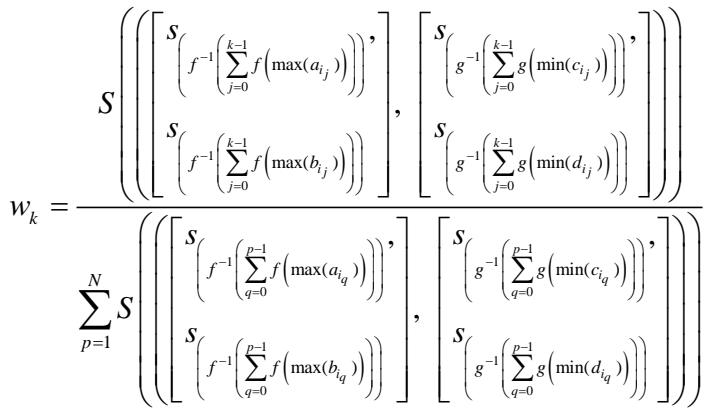


According to the operational law in Eq. (5), we have

$$
w_{k} \alpha_{i_{k}}=\left(\left[\begin{array}{c}
s_{\left(g^{-1}\left(w_{k} g\left(a_{i_{k}}\right)\right)\right)}, \\
s_{\left(g^{-1}\left(w_{k} g\left(b_{i_{k}}\right)\right)\right)}
\end{array}\right],\left[\begin{array}{c}
s_{\left(f^{-1}\left(w_{k} f\left(c_{i_{k}}\right)\right)\right)}, \\
s_{\left(f^{-1}\left(w_{k} f\left(d_{i_{k}}\right)\right)\right)}
\end{array}\right]\right)
$$

According to the operational law in Eq. (3), we can obtain

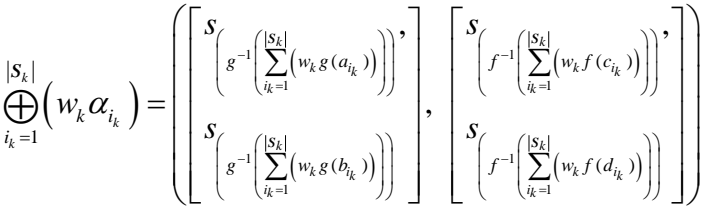

$$
\begin{aligned}
& \bigoplus_{k=1}^{N} \bigoplus_{i_{k}=1}^{\left|S_{k}\right|}\left(w_{k} \alpha_{i_{k}}\right)=
\end{aligned}
$$

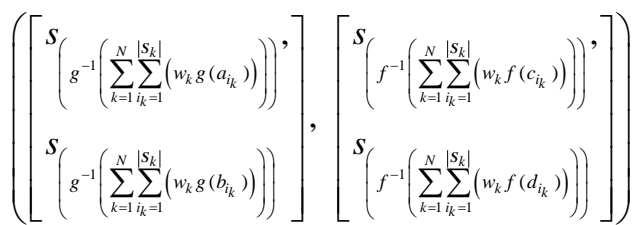

which complete the proof of the theorem.

\section{Proof of Theorem 4}

Proof: According to Theorem 3, we have

$$
\operatorname{LIVIFAPO}\left(\alpha_{1}, \alpha_{2}, \ldots, \alpha_{n}\right)=
$$

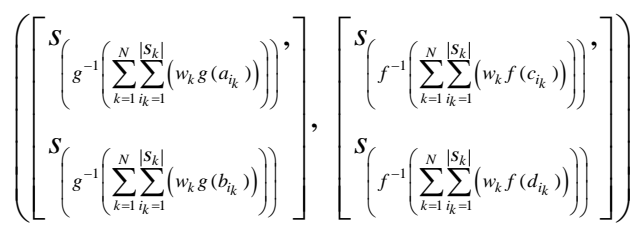

where

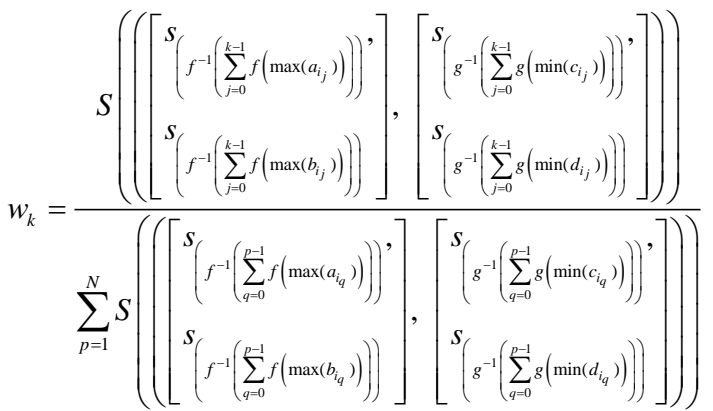

Because $\alpha_{i}=\alpha=\left(\left[s_{a}, s_{b}\right],\left[s_{c}, s_{d}\right]\right)$ for all $i=1,2, \ldots, n$, we can obtain

$$
\begin{gathered}
S_{\left(g^{-1}\left(\sum_{k=1}^{N} \sum_{i_{k}=1}^{S_{k} \mid}\left(w_{k} g\left(a_{i_{k}}\right)\right)\right)\right)}=S_{\left(g^{-1}\left(\left(\sum_{k=1}^{N} w_{k}\right) g(a)\right)\right)}=S_{\left(g^{-1}(g(a))\right)}=S_{a} \\
S_{\left(g^{-1}\left(\sum_{k=1}^{N} \sum_{i_{k}=1}^{\left|S_{k}\right|}\left(w_{k} g\left(b_{i_{k}}\right)\right)\right)\right)}=S_{\left(g^{-1}\left(\left(\sum_{k=1}^{N} w_{k}\right) g(b)\right)\right)}=s_{\left(g^{-1}(g(b))\right)}=S_{b}
\end{gathered}
$$

$$
\begin{aligned}
& s_{\left(f^{-1}\left(\sum_{k=1}^{N} \sum_{i k=1}^{\left|S_{k}\right|}\left(w_{k} f\left(c_{i_{k}}\right)\right)\right)\right)}=s_{\left(f^{-1}\left(\left(\sum_{k=1}^{N} w_{k}\right) f(c)\right)\right)}=s_{\left(f^{-1}(f(c))\right)}=s_{c} \\
& s_{\left(f^{-1}\left(\sum_{k=1}^{N} \sum_{k=1}^{\left|S_{k}\right|}\left(w_{k} f\left(d_{i_{k}}\right)\right)\right)\right)}=s_{\left(f^{-1}\left(\left(\sum_{k=1}^{N} w_{k}\right) f(d)\right)\right)}=s_{\left(f^{-1}(f(d))\right)}=s_{d}
\end{aligned}
$$

Therefore, we have LIVIFAPO $\left(\alpha_{1}, \alpha_{2}, \ldots, \alpha_{n}\right)=\left(\left[s_{a}\right.\right.$, $\left.\left.s_{b}\right],\left[s_{c}, s_{d}\right]\right)$. This completes the proof of the theorem.

\section{References}

[1] S. Greco, J. Figueira, and M. Ehrgott, Multiple Criteria Decision Analysis: State of the Art Surveys, Springer-Verlag New York, New York, 2016.

[2] C. Kahraman, ed., Fuzzy Multi-Criteria Decision Making: Theory and Applications with Recent Developments, Springer Science \& Business Media, New York, 2008.

[3] L.A. Zadeh, Fuzzy Sets, Information and Control 8(3) (1965), 338-353.

[4] K.T. Atanassov, Intuitionistic fuzzy sets, Fuzzy Sets and Systems 20(1) (1986) 87-96.

[5] K.T. Atanassov and G. Gargov, Interval-Valued Intuitionistic Fuzzy Sets, Fuzzy Sets and Systems 31(3) (1989) 343-349.

[6] Z. Chen, P. Liu, and Z. Pei, An approach to multiple attribute group decision making based on linguistic intuitionistic fuzzy numbers, International Journal of Computational Intelligence Systems 8(4) (2015) 747-760.

[7] P. Liu and X. Qin, A New Decision-Making Method Based on Interval-Valued Linguistic Intuitionistic Fuzzy Information, Cognitive Computation 11(1) (2019) 125-144.

[8] H. Garg and K. Kumar, Linguistic interval-valued Atanassov intuitionistic fuzzy sets and their applications to group decision-making problems, IEEE Transactions on Fuzzy Systems 27(12) (2019) 2302-2311.

[9] H. Bustince, E. Barrenechea, M. Pagola, J. Fernandez, Z. Xu, B. Bedregal, J. Montero, H. Hagras, F. Herrera, and B. De Baets, A Historical Account of Types of Fuzzy Sets and Their Relationships, IEEE Transactions on Fuzzy Systems 24(1) (2016) 179-194.

[10] K. Kumar and H. Garg, Prioritized linguistic interval-valued aggregation operators and their applications in group decisionmaking problems, Mathematics 6(10) (2018) 209.

[11]H. Garg and K. Kumar, An extended technique for order preference by similarity to ideal solution group decision-making method with linguistic interval-valued intuitionistic fuzzy information, Journal of Multi-Criteria Decision Analysis 26(12) (2019) 16-26.

[12] J. Tang, F. Meng, F.J. Cabrerizo, and E. Herrera-Viedma, A procedure for group decision making with interval-valued intuitionistic linguistic fuzzy preference relations, Fuzzy Optimization and Decision Making 18(4) (2019) 493-527.

[13]H. Garg and K. Kumar, Group decision making approach based on possibility degree measure under linguistic intervalvalued intuitionistic fuzzy set environment, Journal of Industrial \& Management Optimization 16(1) (2020) 445-467.

[14]Z. Ren, Z. Xu, and H. Wang, The Strategy Selection Problem on Artificial Intelligence with an Integrated VIKOR and AHP Method under Probabilistic Dual Hesitant Fuzzy Information, IEEE Access 7(2019) 103979-103999.

[15] J. Wang, G. Wei, and M. Lu, An extended VIKOR method for multiple criteria group decision making with triangular fuzzy neutrosophic numbers, Symmetry 10(10) (2018) 497. 
[16]S. Zeng, S.M. Chen, and L.W. Kuo, Multiattribute decision making based on novel score function of intuitionistic fuzzy values and modified VIKOR method, Information Sciences 488 (2019) 76-92.

[17]D. Liang, Y. Zhang, Z. Xu, and A. Jamaldeen, Pythagorean fuzzy VIKOR approaches based on TODIM for evaluating internet banking website quality of Ghanaian banking industry, Applied Soft Computing 78 (2019) 583-594.

[18]C.Y. Wang and S.M. Chen, Multiple attribute decision making based on interval-valued intuitionistic fuzzy sets, linear programming methodology, and the extended TOPSIS method, Information Sciences 397 (2017) 155-167.

[19]D. Liang, Z. Xu, D. Liu, and Y. Wu, Method for three-way decisions using ideal TOPSIS solutions at Pythagorean fuzzy information, Information Sciences 435 (2018) 282-295.

[20] S. Zeng, S.M. Chen, and K.Y. Fan, Interval-valued intuitionistic fuzzy multiple attribute decision making based on nonlinear programming methodology and TOPSIS method, Information Sciences $\mathbf{5 0 6}$ (2020) 424-442.

[21] M. Akram, N. Waseem, and P. Liu, Novel Approach in Decision Making with m-Polar Fuzzy ELECTRE-I, International Journal of Fuzzy Systems 21(4) (2019) 1117-1129.

[22] M. Akram, F. Ilyas, and H. Garg, Multi-criteria group decision making based on ELECTRE-I method on Pythagorean fuzzy information, Soft Computing (2019) doi: 10.1007/s00500-019 $-04105-0$

[23]P. Liu, S. Cheng, and Y. Zhang, An extended multi-criteria group decision-making PROMETHEE method based on probability multi-valued neutrosophic Sets, International Journal of Fuzzy Systems 21(2) (2019) 388-406.

[24] Y. Huang and G. Wei, TODIM method for Pythagorean 2tuple linguistic multiple attribute decision making, Journal of Intelligent \& Fuzzy Systems 35(1) (2018) 901-915.

[25]P. Liu and F. Teng, Probabilistic linguistic TODIM method for selecting products through online product reviews, Information Sciences 485 (2019) 441-455.

[26]P. Liu and S.M. Chen, Group decision making based on Heronian aggregation operators of intuitionistic fuzzy numbers, IEEE Transactions on Cybernetics 47(9) (2017) 2514-2530.

[27]Z. Li, H. Gao, and G. Wei, Methods for multiple attribute group decision making based on intuitionistic fuzzy Dombi Hamy mean operators, Symmetry 10(11) (2018) 574.

[28]P. Liu, J. Liu, and S.M. Chen, Some intuitionistic fuzzy Dombi Bonferroni mean operators and their application to multiattribute group decision making, Journal of the Operational Research Society 69(1) (2018) 1-24.

[29]P. Wang and P. Liu, Some Maclaurin symmetric mean aggregation operators based on Schweizer-Sklar operations for intuitionistic fuzzy numbers and their application to decision making, Journal of Intelligent \& Fuzzy Systems 36(4) (2019) 3801 -3824 .

[30] M. Shi, F. Yang, and Y. Xiao, Intuitionistic fuzzy power geometric Heronian mean operators and their application to multiple attribute decision making, Journal of Intelligent \& Fuzzy Systems 37(2) (2019) 2651-2669.

[31] H. Garg, Some robust improved geometric aggregation operators under interval-valued intuitionistic fuzzy environment for multi-criteria decision-making process, Journal of Industrial \& Management Optimization 14(1) (2018) 283-308.

[32] M. Wen, H. Zhao, Z. Xu, and Q. Lei, Definite integrals for aggregating continuous interval-valued intuitionistic fuzzy information, Applied Soft Computing 70 (2018) 875-895.

[33]L. Wu, G. Wei, H. Gao, and Y. Wei, Some interval-valued intuitionistic fuzzy Dombi Hamy mean operators and their application for evaluating the elderly tourism service quality in tourism destination, Mathematics 6(12) (2018) 294.
[34]P. Liu, J. Liu, and J.M. Merigó, Partitioned Heronian Means Based on Linguistic Intuitionistic Fuzzy Numbers for Dealing with Multi-Attribute Group Decision Making, Applied Soft Computing 62 (2018) 395-422.

[35]H. Peng, J. Wang, and P. Cheng, A linguistic intuitionistic multi-criteria decision-making method based on the Frank Heronian mean operator and its application in evaluating coal mine safety, International Journal of Machine Learning and Cybernetics 9 (2018) 1053-1068.

[36] M. Lin, J. Wei, Z. Xu, and R. Chen, Multiattribute Group Decision-Making Based on Linguistic Pythagorean Fuzzy Interaction Partitioned Bonferroni Mean Aggregation Operators, Complexity 2018 (2018) 9531064

[37] Y. Zhong, X. Guo, H. Gao, Y. Qin, M. Huang, and X. Luo, A new multi-criteria decision-making method based on Pythagorean hesitant fuzzy Archimedean Muirhead mean operators, Journal of Intelligent \& Fuzzy Systems 37(4) (2019) 55515571.

[38] Y. Zhong, H. Gao, X. Guo, Y. Qin, M. Huang, and X. Luo, Dombi power partitioned Heronian mean operators of q-rung orthopair fuzzy numbers for multiple attribute group decision making, PLoS One 14(10) (2019) e0222007.

[39] Y. Qin, Q. Qi, P.J. Scott, and X. Jiang, Multi-criteria group decision making based on Archimedean power partitioned Muirhead mean operators of q-rung orthopair fuzzy numbers, PloS One 14(9) (2019) e0221759.

[40] Y. Qin, X. Cui, M. Huang, Y. Zhong, Z. Tang, and P. Shi, Archimedean Muirhead Aggregation Operators of q-Rung Orthopair Fuzzy Numbers for Multicriteria Group Decision Making, Complexity 2019 (2019) 3103741.

[41]P. Liu and P. Wang, Multiple-Attribute Decision Making Based on Archimedean Bonferroni Operators of q-Rung Orthopair Fuzzy Numbers, IEEE Transactions on Fuzzy Systems 27(5) (2019) 834-848.

[42]L. Sun, H. Dong, and A. Liu, Aggregation functions considering criteria interrelationships in fuzzy multi-criteria decision making: state-of-the-art, IEEE Access 6 (2018) 68104-68136.

[43]R.R. Yager, Prioritized aggregation operators, International Journal of Approximate Reasoning 48(1) (2008) 263-274.

[44]B. Li and W. He, Intuitionistic fuzzy PRI-AND and PRI-OR aggregation operators, Information Fusion 14(4) (2013) 450459.

[45]X. Yu and Z. Xu, Prioritized intuitionistic fuzzy aggregation operators, Information Fusion 14(1) (2013) 108-116.

[46] G. Wei, Hesitant fuzzy prioritized operators and their application to multiple attribute decision making, Knowledge-Based Systems 31 (2012) 176-182.

[47]C. Wei, Z. Ren, X. Tang, and J. Feng, Information aggregation operators based on hesitant fuzzy sets and prioritization relationship, Journal of Intelligent \& Fuzzy Systems 31(2) (2016) 765-774.

[48]H. Gao, Pythagorean fuzzy Hamacher prioritized aggregation operators in multiple attribute decision making, Journal of Intelligent \& Fuzzy Systems 35(2) (2018) 2229-2245.

[49] M.S. Ali Khan, S. Abdullah, and A. Ali, Multiattribute group decision-making based on Pythagorean fuzzy Einstein prioritized aggregation operators, International Journal of Intelligent Systems 34(5) (2019) 1001-1033.

[50]H. Garg and Nancy, Multi-Criteria Decision-Making Method Based on Prioritized Muirhead Mean Aggregation Operator under Neutrosophic Set Environment, Symmetry 10(7) (2018) 280.

[51]C. Jana, M. Pal, and J. Wang, Bipolar fuzzy Dombi prioritized aggregation operators in multiple attribute decision making, Soft Computing (2019) doi: 10.1007/s00500-019-04130-z. 
[52]H. Garg and R. Arora, Novel Scaled Prioritized Intuitionistic Fuzzy Soft Interaction Averaging Aggregation Operators and Their Application to Multi Criteria Decision Making, Engineering Applications of Artificial Intelligence 71 (2018) 100112.

[53]H. Gao, G. Wei, and Y. Huang, Dual Hesitant Bipolar Fuzzy Hamacher Prioritized Aggregation Operators in Multiple Attribute Decision Making, IEEE Access 6 (2017) 11508-11522.

[54]R. Arora and H. Garg, Group decision-making method based on prioritized linguistic intuitionistic fuzzy aggregation operators and its fundamental properties. Computational and Applied Mathematics 38(2) (2019) 36.
[55]N. Zhao, Z. Xu, and Z. Ren, Hesitant fuzzy linguistic prioritized superiority and inferiority ranking method and its application in sustainable energy technology evaluation, Information Sciences 478 (2019) 239-257.

[56] G. Wei and Y. Wei, Some single-valued neutrosophic Dombi prioritized weighted aggregation operators in multiple attribute decision making, Journal of Intelligent \& Fuzzy Systems 35(2) (2018) 2001-2013.

[57] K. Kumar and H. Garg, Prioritized linguistic interval-valued aggregation operators and their applications in group decisionmaking problems, Mathematics 6(10) (2018) 209.

[58]E.P. Klement, R. Mesiar, and E. Pap, Triangular Norms, Kluwer Academic Publishers, Dordrecht, 2000. 